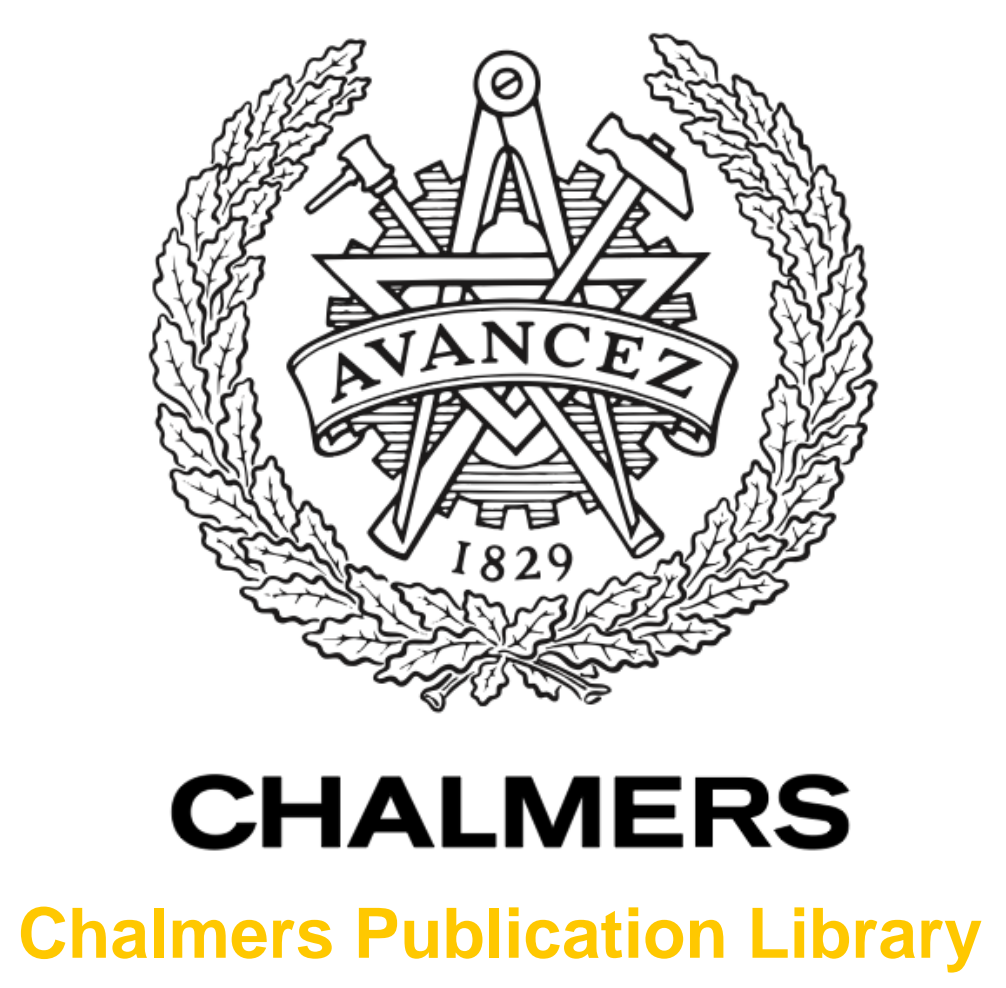

Potassium, chlorine, and sulfur in ash, particles, deposits, and corrosion during wood
combustion in a circulating fluidized-bed boiler

This document has been downloaded from Chalmers Publication Library (CPL). It is the author's version of a work that was accepted for publication in:

Energy \& Fuels (ISSN: 0887-0624)

Citation for the published paper:

Davidsson, K. ; Åmand, L. ; Leckner, B. et al. (2007) "Potassium, chlorine, and sulfur in ash, particles, deposits, and corrosion during wood combustion in a circulating fluidized-bed boiler". Energy \& Fuels, vol. 21(1), pp. 71-81.

http://dx.doi.org/10.1021/ef060306c

Downloaded from: http://publications.lib.chalmers.se/publication/66054

Notice: Changes introduced as a result of publishing processes such as copy-editing and formatting may not be reflected in this document. For a definitive version of this work, please refer to the published source. Please note that access to the published version might require a subscription. 


\section{Article}

Potassium, Chlorine, and Sulfur in Ash, Particles, Deposits, and Corrosion during Wood Combustion in a Circulating Fluidized-Bed Boiler

Kent O. Davidsson, Lars-Erik mand, and Bo LecknerBorka Kovacevik, Maria Svane, Magnus Hagstrm, and Jan B. C. PetterssonJesper Pettersson, Henrik Asteman, Jan-Erik Svensson, and Lars-Gunnar Johansson

Energy Fuels, 2007, 21 (1), 71-81 • DOI: 10.1021/ef060306c

Downloaded from http://pubs.acs.org on January 9, 2009

\section{More About This Article}

Additional resources and features associated with this article are available within the HTML version:

- $\quad$ Supporting Information

- Access to high resolution figures

- $\quad$ Links to articles and content related to this article

- $\quad$ Copyright permission to reproduce figures and/or text from this article

\section{View the Full Text HTML}

\section{ACS Publications}




\title{
Potassium, Chlorine, and Sulfur in Ash, Particles, Deposits, and Corrosion during Wood Combustion in a Circulating Fluidized-Bed Boiler
}

\author{
Kent O. Davidsson,* Lars-Erik Åmand, and Bo Leckner \\ Department of Energy and Environment, Energy Conversion, Chalmers University of Technology, \\ SE-41296 Göteborg, Sweden \\ Borka Kovacevik, Maria Svane, Magnus Hagström, and Jan B. C. Pettersson \\ Department of Chemistry, Atmospheric Science, Göteborg University, SE-412 96 Göteborg, Sweden
}

Jesper Pettersson, Henrik Asteman,${ }^{\dagger}$ Jan-Erik Svensson, and Lars-Gunnar Johansson

Department of Chemical and Biological Engineering, Environmental Inorganic Chemistry, The High-Temperature Corrosion Centre, Chalmers University of Technology, SE-412 96 Sweden

Received June 30, 2006. Revised Manuscript Received September 27, 2006

\begin{abstract}
The effect of the addition of chlorine and/or sulfur to the fuel on fly ash composition, deposit formation, and superheater corrosion has been studied during biomass combustion in a circulating fluidized-bed boiler. The chlorine $(\mathrm{HCl}(\mathrm{aq}))$ and sulfur $\left(\mathrm{SO}_{2}(\mathrm{~g})\right)$ were added in proportions of relevance for the potassium chemistry. The composition of the bottom and the fly ashes was analyzed. Gas and particle measurements were performed downstream of the cyclone before the convection pass and the flue gas composition was recorded in the stack with a series of standard instruments and an FTIR analyzer. At the position downstream of the cyclone, a deposit probe was situated, simulating a superheater tube. Deposits on the probe and initial corrosion were examined. It is concluded that addition of sulfur and chlorine increases the formation of submicron particles leading to deposition of potassium sulfate and chloride. The results compare well with earlier work based on laboratory-scale experiments concerning effects of chlorine and sulfur on potassium chemistry.
\end{abstract}

\section{Introduction}

During firing of biomass in boilers for power generation, inorganic components are released from the fuel and may cause problems such as deposits ${ }^{1-5}$ with subsequent high-temperature corrosion $^{4,6-8}$ and agglomeration of bed material in fluidized beds. ${ }^{9}$ Deposits are formed from alkali metals that are released from the fuel and transported to surfaces in the boiler by different mechanisms. ${ }^{3,6,10}$ Deposits may be sticky at relatively

* To whom correspondence should be addressed. Phone: +46 31772 14 53. Fax: +46 3177235 92. E-mail: keda@entek.chalmers.se.

$\dagger$ Present address: Max-Planck-Institut für Eisenforschung GmbH, MaxPlanck-Strasse 1, D-40237 Düsseldorf, Germany.

(1) Miles, T. R.; Miles, T. R., Jr.; Baxter, L. L.; Bryers, R. W.; Jenkins, B. M.; Oden, L. L. Biomass Bioenergy 1996, 10, 125-138.

(2) Baxter, L. L.; Miles, T. R.; Miles, T. R., Jr.; Jenkins, B. M.; Milne, T.; Dayton, D.; Bryers, R. W.; Oden, L. L. Fuel Process. Technol. 1998, $54,47-78$.

(3) Baxter, L. L. Biomass Bioenergy 1993, 4, 85-102.

(4) Michelsen, H. P.; Frandsen, F.; Dam-Johansen, K.; Larsen, O. H. Fuel Process. Technol. 1998, 54, 95-108.

(5) Jensen, P. A.; Frandsen, F. J.; Hansen, J.; Dam-Johansen, K.; Henriksen, N.; Hörlyck, S. Energy Fuels 2004, 18, 378-384.

(6) Nielsen, H. P.; Frandsen, F. J.; Dam-Johansen, K.; Baxter, L. L. Prog. Energy Combust. Sci. 2000, 26, 283-298.

(7) Spiegel, M. Mater. High Temp. 1997, 14, 221-226.

(8) Pettersson, J.; Pettersson, C.; Folkesson, N.; Johansson, L.-G.; Skog,

E.; Svensson, J.-E. Mater. Sci. Forum 2006, 522-523, 563-570.

(9) Lin, W.; Dam-Johansen, K.; Frandsen, F. J. Chem. Eng. J. 2003, 96, $171-185$.

(10) Kaufmann, H.; Nussbaumer, T.; Baxter, L.; Yang, N. Fuel 2000, $79,141-151$. low temperatures, and this may facilitate further attachment of particles. Once a deposit including alkali metals has been formed, corrosion may be enhanced ${ }^{6,11,12}$ and the super heater tubes may have to be replaced, implying costly shutdown and repair.

To counteract the alkali-related problems, it is important to know how alkali is transported from the fuel to the surface where it deposits. In biomass, potassium is the dominant alkali element. Chlorine has been found to facilitate alkali release from biofuel, ${ }^{13}$ probably by forming gaseous potassium chloride, which is stable at combustion temperatures. ${ }^{2}$ Potassium chloride may then condense on particles in the flue gas or on surfaces, forming a corrosive deposit. ${ }^{6,11,12}$ If chlorine is not present, potassium may form hydroxide when released from the fuel ${ }^{2,14}$ and, in fluidized beds, it may also react with the bed material. ${ }^{15}$

Several methods have been suggested to counteract the alkalirelated deposits. These are removal of alkali in the fuel, e.g., by washing, ${ }^{16}$ addition of kaolin to capture potassium, ${ }^{17,18}$ and

(11) Pettersson, J.; Asteman, H.; Svensson, J.-E.; Johansson, L.-G. Oxid. Met. 2005, 64, 23-41.

(12) Pettersson, C.; Pettersson, J.; Asteman, H.; Svensson, J.-E.; Johansson, L.-G. Corros. Sci. 2006, 48, 1368-1378.

(13) Olsson, J. G.; Jäglid, U.; Pettersson, J. B. C.; Hald, P. Energy Fuels 1997, 11, 779-784.

(14) Westberg, H. M.; Byström, M.; Leckner, B. Energy Fuels 2003, $17,18-28$.

(15) Öhman, M.; Nordin, A.; Skrifvars, B.-J.; Backman, R.; Hupa, M. Energy Fuels 2000, 14, 169-178. 


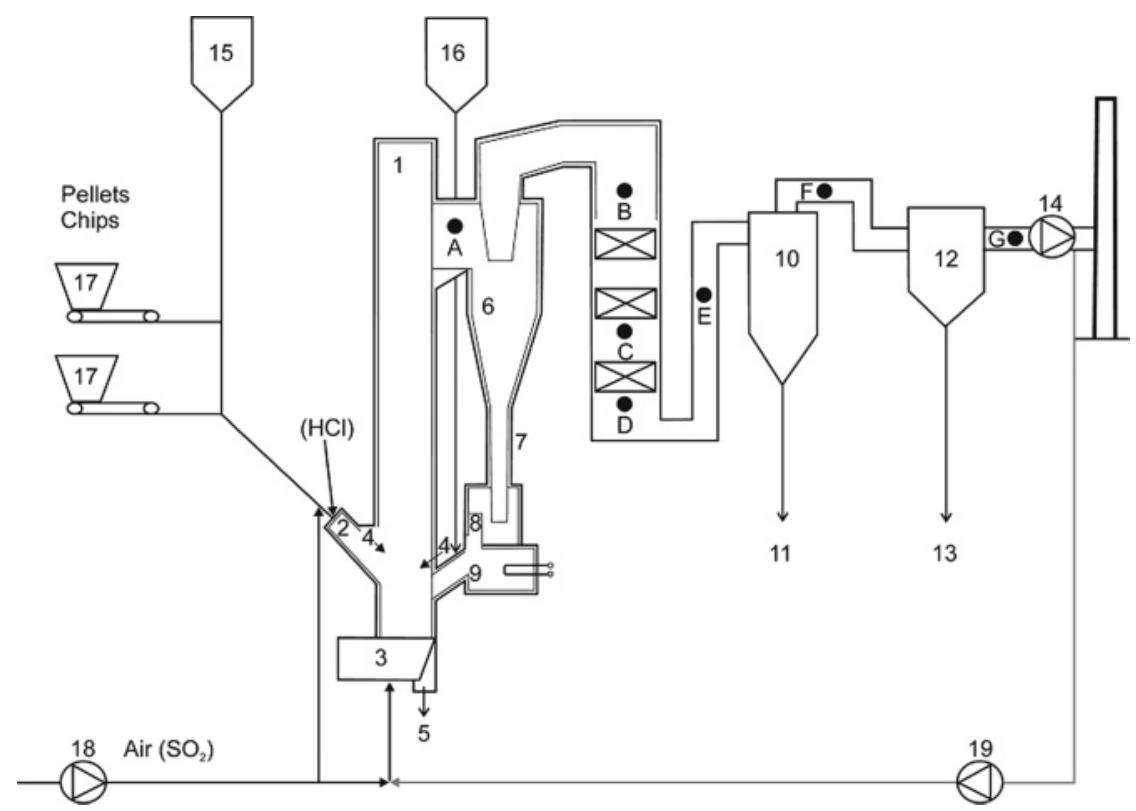

Figure 1. Schematic description of the CFB: (1) combustion chamber; (2) fuel feed chute; (3) primary air to air plenum; (4) secondary air inlet at $2.1 \mathrm{~m}$; (5) bottom ash removal; (6) hot primary cyclone; (7) particle return leg; (8) particle seal; (9) heat exchanger; (10) cold secondary cyclone; (11) secondary cyclone ash removal; (12) bag filters; (13) filter ash removal; (14) flue gas fan; (15) sand bin; (16) lime bin; (17) fuel bunkers; (18) air fan; and (19) flue gas recirculation fan. Measurement positions A, B, C, D, E, F, and G are indicated.

cofiring with other fuels that contain sulfur or kaolin-like ash minerals. ${ }^{19}$ It has been shown that addition of sulfur enhances formation of potassium sulfate and thereby hinders formation of potassium chloride. , $20,21^{\text {Apart from cofiring with fuels }}$ containing sulfur, e.g., coal, sulfur can be added to the combustion chamber or the flue gas stream as elementary sulfur, sulfur dioxide, ${ }^{7,22}$ or sulfate..$^{23}$

In the present study, potassium, chlorine, and sulfur distributions between ash, particles in the combustor system, vapor, and deposits are examined during combustion of wood chips and wood pellets in a circulating fluidized bed (CFB). The effect of sulfur and chlorine additions on initial corrosion of superheater steel is investigated. In a related earlier study in the same $\mathrm{CFB}$, potassium, chlorine, and sulfur distributions between ash and vapor were studied during co-combustion of wood chips and coal. ${ }^{14}$

\section{Experimental Details}

Boiler. Measurements were performed in the $12 \mathrm{MW}_{\text {th }} \mathrm{CFB}$ boiler at Chalmers University of Technology. The boiler, schematically shown in Figure 1, was fired with a mixture of wood chips (62-75\%) and wood pellets $(25-38 \%)$ at a load of 7-7.5 $\mathrm{MW}_{\mathrm{th}}$. The excess-air ratio was held in the range of $1.22-1.25$. The bed temperature was kept at $850 \pm 10^{\circ} \mathrm{C}$. The flue gas was $\sim 800{ }^{\circ} \mathrm{C}$ upstream and $\sim 160{ }^{\circ} \mathrm{C}$ downstream of

(16) Davidsson, K. O.; Korsgren, J. G.; Pettersson, J. B. C.; Jäglid, U. Fuel 2002, 81, 137-142.

(17) Engvall, K. Värmeforsk Service AB, Report no. 742, 2001. 76.

(18) Steenari, B.-M.; Lindqvist, O. Biomass Bioenergy 1998, 14, 67-

(19) Aho, M.; Ferrer, E. Fuel 2005, 84, 201-212.

(20) Iisa, K.; Lu, Y.; Salmenoja, K. Energy Fuels 1999, 13, 1184-1190.

(21) Hansen, L. A.; Nielsen, H. P.; Frandsen, F. J.; Dam-Johansen, K. Hörlykk, S.; Karlsson, A. Fuel Process. Technol. 2000, 64, 189-209.

(22) Nielsen, H. P.; Baxter, L. L.; Sclippab, G.; Frandsen, F. J.; DamJohansen, K. Fuel 2000, 79, 131-139.

(23) Henderson, P. J.; Andersson, C.; Kassman, H.; Högberg, J. Reducing superheater corrosion in wood-fired power plant. In Baltica VI, Life management and maintenance for power plants, Proceedings of VTT Symposium; Veivo, J., Auerkari, P., Eds.; VTT Technical Research Center of Finland: VTT, Finland, 2004; pp 143-154.
Table 1. Fuel Analyses (with Standard Deviation)

\begin{tabular}{lcl}
\hline & wood chips & wood pellets \\
\hline & proximate analysis \\
moisture as received & $45.57 \pm 2.86$ & $8.85 \pm 2.71$ \\
ash (wt \% dry) & $0.70 \pm 0.22$ & $0.6 \pm 0.12$ \\
\multicolumn{3}{c}{ ultimate analysis (wt \% dry) } \\
$\mathrm{C}$ & $49.27 \pm 0.48$ & $49.67 \pm 0.12$ \\
$\mathrm{H}$ & $6.00 \pm 0.11$ & 6.0 \\
$\mathrm{O}$ & $43.90 \pm 0.11$ & $43.73 \pm 0.06$ \\
$\mathrm{~S}$ & $<0.01$ & $<0.01$ \\
$\mathrm{~N}$ & $0.12 \pm 0.04$ & $0.08 \pm 0.02$ \\
$\mathrm{Cl}$ & $<0.01$ & $<0.01$ \\
$\mathrm{lower}$ heating value (MJ/kg) & $18.63 \pm 0.18$ & $18.85 \pm 0.05$ \\
& & \\
$\mathrm{~K}$ & fuel ash analysis & $(\mathrm{wt} \%$ of dry ash) \\
$\mathrm{Na}$ & $12.92 \pm 1.55$ & $8.62 \pm 2.20$ \\
$\mathrm{Al}$ & $0.47 \pm 0.31$ & $0.71 \pm 0.20$ \\
$\mathrm{Si}$ & $1.17 \pm 1.05$ & $1.16 \pm 0.70$ \\
$\mathrm{Fe}$ & $2.55 \pm 1.80$ & $10.24 \pm 5.88$ \\
$\mathrm{Ca}$ & $0.63 \pm 0.59$ & $0.99 \pm 0.41$ \\
$\mathrm{Mg}$ & $21.5 \pm 2.26$ & $18.5 \pm 1.46$ \\
$\mathrm{P}$ & $3.38 \pm 0.53$ & $3.06 \pm 0.30$ \\
$\mathrm{Ti}$ & $1.41 \pm 0.37$ & $1.08 \pm 0.20$ \\
$\mathrm{~S}$ & $0.06 \pm 0.05$ & $0.06 \pm 0.03$ \\
$\mathrm{Cl}$ & $0.8 \pm 0.21$ & $0.62 \pm 0.12$ \\
& $0.02 \pm 0.01$ & $0.04 \pm 0.04$ \\
& & \\
& & \\
& & \\
& &
\end{tabular}

the convection pass. The bed sand was "silversand", which consists of $98.9 \%$ quartz $\left(\mathrm{SiO}_{2}\right)$. Given as oxides, other constituents are $\mathrm{Al}_{2} \mathrm{O}_{3}(0.181 \%), \mathrm{Fe}_{2} \mathrm{O}_{3}, \mathrm{CaO}, \mathrm{MgO}$ (each $\sim 0.12 \%)$, and $\mathrm{K}_{2} \mathrm{O}(0.06 \%){ }^{24}$

The fuel flow was continuously recorded, and fuel samples were taken at least twice during an experiment. Fuel analyses are shown in Table 1. Experiments were performed either with the fuel mixture of wood chips and pellets alone or with addition of chlorine as $\mathrm{HCl}$ (aq) and/or sulfur as $\mathrm{SO}_{2}(\mathrm{~g})$. Ash samples were taken at the end of each experiment from the bottom bed (labeled 5 in Figure 1), the return leg (7), the secondary cyclone (11), and the bag filters (12), as indicated in Figure 1. The samples were melted in lithium borate and thereafter dissolved

(24) Eklund, A.; Brus, E.; Öhman, M.; Hedman, H.; Boström, D.; Nordin, A. Värmeforsk Service AB, Report no. 832, 2003. 


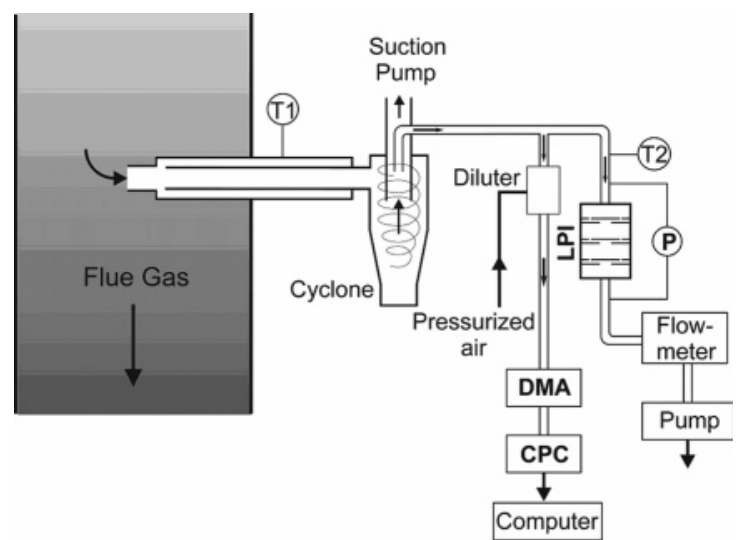

Figure 2. Setup for on-line sampling and analysis of particles from the flue gas, including a differential mobility analyzer (DMA) connected to a condensation particle counter (CPC) and a low-pressure impactor (LPI) used to collect samples for subsequent analysis of mass and chemical composition. Abbreviations: $\mathrm{T} 1, \mathrm{~T} 2=$ thermocouples; $\mathrm{P}=$ pressure gauge.

in nitric acid. The solution was analyzed with inductively coupled plasma-optical emission spectroscopy. The ash flows to and from the boiler were measured. However, the output of ash is small and only a few $\mathrm{kg} \mathrm{h}^{-1}$ were measured with equipment devised for $10-50 \times$ larger flows. Furthermore, the low ash content of the fuels makes representative fuel sampling difficult, owing to a rather large spread of ash content in different fuel samples, and it is concluded that the measured fuel ash flows have an uncertainty of $20-25 \%$. The flue gas in positions $\mathrm{B}$, E, and $\mathrm{G}$ was continuously monitored by two sets of conventional on-line gas analyzers for $\mathrm{O}_{2}, \mathrm{CO}, \mathrm{CO}_{2}$, and $\mathrm{SO}_{2}$ and an FTIR (Fourier Transform Infrared, Bomem M110) for $\mathrm{H}_{2} \mathrm{O}, \mathrm{CO}_{2}, \mathrm{SO}_{2}, \mathrm{CO}$, and $\mathrm{HCl}$. The gas analyzers were calibrated before each experiment.

Particle Sampling. Particles were collcted at position B after the exit of the primary cyclone at a gas temperature of $\sim 800$ ${ }^{\circ} \mathrm{C}$ and at position $\mathrm{F}$ downstream of the secondary cyclone at $\sim 160{ }^{\circ} \mathrm{C}$. The instrumental setup for on-line particle sampling is illustrated in Figure 2.

A sampling probe inlet that was oriented perpendicularly to the flue gas flow extracted gas at the center of the flue gas duct. The losses to surfaces in the probe, as well as the reduction of flue gas temperature, were considered to be limited since the flow rate through the probe was typically $200 \mathrm{dm}^{3} / \mathrm{min}$ and the residence time within the probe was $<0.2 \mathrm{~s}$. Particles with a diameter larger than $3 \mu \mathrm{m}$ were partially removed by a cyclone connected to the probe, whose removal probability increases with particle size. Because of the high particle number concentrations, dilution of the hot flue gas during aerosol particle measurements was accomplished by three ejector diluters connected in series before the measurement instruments, resulting in a total dilution factor of 350. The first diluter was heated to $150{ }^{\circ} \mathrm{C}$ to avoid condensation of water vapor. Number size distributions were obtained for particles in the size range $0.01-$ $0.35 \mu \mathrm{m}$ with a scanning mobility particle-sizer system (SMPS, TSI Inc., model 3936). A low-pressure impactor (LPI) was used to collect particles to obtain information on mass and chemical composition. Particles were inertially separated and collected on 11 steel plates prepared with vacuum grease dissolved in toluene. The mass from particles collected on each plate was measured, and the particles were further dissolved in $1 \% \mathrm{HNO}_{3}$ for subsequent elemental analysis by inductively coupled plasma-mass spectroscopy (ICP-MS).

Deposit/Corrosion Probe. The formation of deposits and the initial corrosion attack in the superheater region were studied
Table 2. Composition of the 304L Alloy Samples in Weight and Molar Percent

\begin{tabular}{lcccccccc}
\hline & $\mathrm{Cr}$ & $\mathrm{Ni}$ & $\mathrm{Mn}$ & $\mathrm{Si}$ & $\mathrm{Mo}$ & $\mathrm{Fe}$ & $n_{\mathrm{Cr}} / n_{\mathrm{Fe}}$ & phase \\
\hline 304L (wt \%) & 18.5 & 10.2 & 1.41 & 0.55 & 0.49 & 68.0 & & $\gamma$ \\
304L (atom \%) & 19.5 & 9.55 & 1.41 & 1.08 & 0.28 & 67.0 & 0.29 & $\gamma$
\end{tabular}

Table 3. Description of the Experimental Cases Studied ${ }^{a}$

\begin{tabular}{lccccc}
\hline $\begin{array}{c}\text { experimental } \\
\text { case }\end{array}$ & $\begin{array}{c}\text { wood chips } \\
(\mathrm{kgDS} / \mathrm{h})\end{array}$ & $\begin{array}{c}\text { pellets } \\
(\mathrm{kgDS} / \mathrm{h})\end{array}$ & $\begin{array}{c}\mathrm{K} \\
(\mathrm{mol} / \mathrm{h})\end{array}$ & $\begin{array}{c}\mathrm{Cl} \\
(\mathrm{mol} / \mathrm{h})\end{array}$ & $\begin{array}{c}\mathrm{S} \\
(\mathrm{mol} / \mathrm{h})\end{array}$ \\
\hline base case $_{\mathrm{Cl} \mathrm{case}}{ }^{b}$ & 1116 & 416 & 30 & 0 & 3.1 \\
$\mathrm{Cl}+\mathrm{S}$ case $^{b, c}$ & 961 & 515 & 34 & 33 & 2.8 \\
$\mathrm{~S} \mathrm{case}^{c}$ & 1079 & 427 & 40 & 34 & 40 \\
& 1133 & 384 & 29 & 0 & 41
\end{tabular}

${ }^{a}$ Values are given as averages from different experimental tests. ${ }^{b}$ Chlorine was supplied by addition of $2-2.5 \mathrm{M} \mathrm{HCl}(\mathrm{aq})$ in addition to fuel-chlorine. ${ }^{c}$ Sulfur was supplied by addition of $\mathrm{SO}_{2}(\mathrm{~g})$ in addition to fuel-sulfur.

using steel rings (diameter of $38 \mathrm{~mm}$, length $15 \mathrm{~mm}$ ) fitted on an air-cooled probe, which was exposed at position B. The rings were made of alloy $304 \mathrm{~L}$ (see elemental composition in Table 2 ). The exposure time was between $15 \mathrm{~min}$ and $12 \mathrm{~h}$. Before exposure, a fresh surface was produced by first turning the rings on a lathe, and thereafter they were subjected to ultrasonic cleaning in acetone and ethanol. The temperature of the sample was measured by a thermocouple shielded from the flue gas and placed on the windward side of the probe a few $\mathrm{mm}$ from the samples. After a heat-up period of $\sim 5 \mathrm{~min}$, the surface temperature of the probe was kept at $500{ }^{\circ} \mathrm{C}$. Crystalline corrosion products were analyzed by X-ray diffraction (XRD) in a Siemens D5000 powder diffractometer equipped with grazing incidence beam attachment and a Göbel mirror. $\mathrm{Cu} \mathrm{K} \alpha$ radiation was used, and the angle of incidence was $10^{\circ}$. The detector measured between $20^{\circ}<2 \theta<60^{\circ}$. Analytical scanning electron microscopy was carried out with an Electro-scan equipped with a Link eX1 EDX system. The microscope was operated at $20 \mathrm{kV}$ for secondary electron imaging and energydispersive X-ray (EDX) analysis. Auger analysis was performed using a scanning Auger microprobe (PHI660). The electron beam voltage was $10 \mathrm{kV}$, and the beam current was $\sim 150 \mathrm{nA}$. Depth profiles were obtained using a differentially pumped ion gun $\left(\mathrm{Ar}^{+}\right)$with acceleration voltage $4 \mathrm{kV}$. The etch rates were calibrated on flat samples of $\mathrm{Ta}_{2} \mathrm{O}_{5}$ with a well-known oxide thickness of $1000 \AA$. The collected raw data were refined by MultiPak v.6.0 software to evaluate the shapes of differentiated Auger peaks. This feature distinguishes between the signals from oxidized and metallic iron and chromium based on the chemical shifts of these elements in oxidized form.

Experimental Strategy. Potassium, chlorine, and sulfur chemistry, and the transport and distribution of these species in the CFB boiler, were studied with and without additives to the fuel. The flows of fuels and the additives into the boiler in the different experiments are summarized in Table 3. Combustion of a mixture of wood chips and wood pellets without additive is referred to as the "base case". The total flows of chlorine (added at the fuel feed chute as $\mathrm{HCl}$ (aq)) and sulfur (added to the primary air as $\mathrm{SO}_{2}(\mathrm{~g})$ ) increase by about an order of magnitude compared to the base case. The additive cases are referred to as the $\mathrm{Cl}, \mathrm{Cl}+\mathrm{S}$, and $\mathrm{S}$ cases, as defined in Table 3 . The added flows of chlorine and sulfur are related to that of potassium, originating from the fuel. Each experiment lasted for $\sim 12 \mathrm{~h}$ to approach steady-state conditions. Prior to each experiment, soot-blowing with steam cleaned the convection pass. 

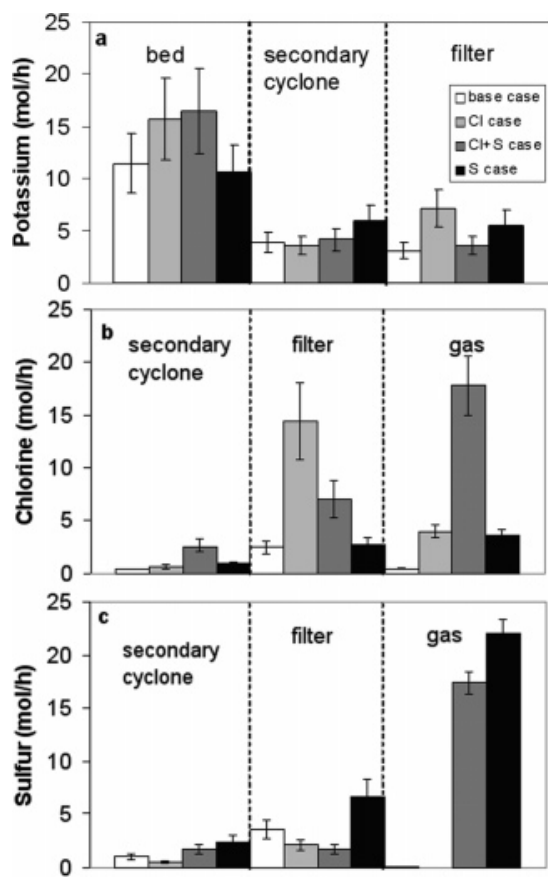

Figure 3. Molar flows at positions 5, 11, 13, and 14 (Figure 1) in the CFB boiler: (a) $\mathrm{K}$, (b) $\mathrm{Cl}$, and (c) $\mathrm{S}$.

\section{Results}

Flows of Solid and Gaseous Species. The ratios of input of fuel ash to the total output of ash were calculated for each case. In the three base-case runs, the ratios were $0.96,1.07$, and 1.18. In the two $\mathrm{Cl}$ cases, the ratios were 1.21 and 1.32 . In the $\mathrm{Cl}+$ $\mathrm{S}$ case, it was 1.44 , and in the two $\mathrm{S}$ cases, they were 0.60 and 0.91. A perfect ash balance would yield a ratio of 1 . Despite the experimental errors of $\sim 25 \%$, there is a tendency that $\mathrm{HCl}$ addition leads to accumulation of ash in the boiler.

The ashes, collected from the secondary cyclone and the filter, are the fly ash. Because of the small ash flows, no significant difference in the ash flows was found between the different cases. The bottom ash flow from the bed was only $0.5-1.5$ $\mathrm{kg} / \mathrm{h}$, but more was removed as fly ash. The flows from the secondary cyclone and bag filter were $3-6$ and $2.5-4 \mathrm{~kg} / \mathrm{h}$, respectively. A shift in the relation between the ash flows from the bag filter and the secondary cyclone is noted when the combustion environment is altered from the $\mathrm{Cl}$ case to the $\mathrm{Cl}$ $+\mathrm{S}$ case. Addition of $\mathrm{HCl}$ results in high ash concentration in the filter, whereas when $\mathrm{HCl}$ is added together with $\mathrm{SO}_{2}$, a larger fraction of the ash is captured in the secondary cyclone.

The molar flows of potassium, chlorine, and sulfur in the ash from the bed, from the secondary cyclone, from the filter, and in the flue gas are shown in Figure 3. As expected, the $\mathrm{SO}_{2}$ concentration increases greatly when $\mathrm{SO}_{2}$ is added, and the corresponding is true for $\mathrm{HCl}$ on addition of $\mathrm{HCl}$. An interesting observation is that the $\mathrm{HCl}$ concentration is very high in the $\mathrm{Cl}+\mathrm{S}$ case and also relatively high in the $\mathrm{S}$ case (compared to the base case that has the same $\mathrm{Cl}$ input). This means that sulfur competes with chlorine in reactions with other components. On the other hand, the potassium flow is not strongly affected by the addition of chlorine and sulfur. Addition of $\mathrm{HCl}$ and/or $\mathrm{SO}_{2}$ increases the total fly ash flow. A sharp increase in chlorine flow from the filter is observed upon $\mathrm{HCl}$ addition; this increase is suppressed upon $\mathrm{SO}_{2}$ addition, and chlorine is instead found as $\mathrm{HCl}$. There is no difference in sulfur flow between the $\mathrm{Cl}$ case and the $\mathrm{Cl}+\mathrm{S}$ case, whereas in the $\mathrm{S}$ case, the sulfur flow increases considerably.
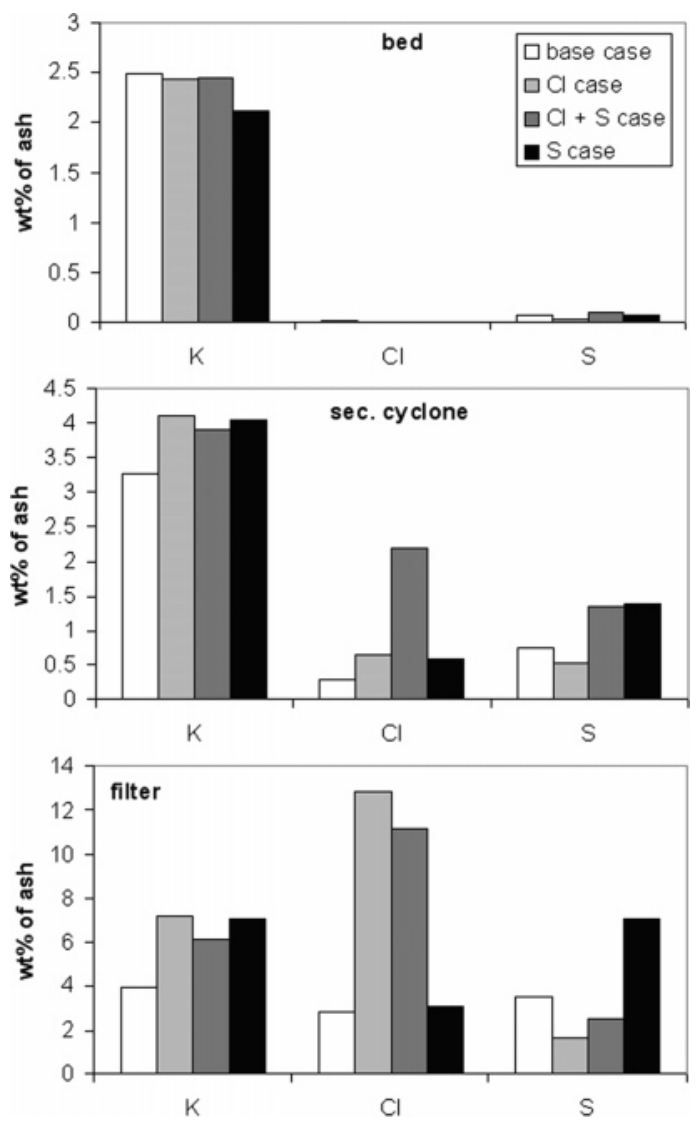

Figure 4. Content of $\mathrm{K}, \mathrm{Cl}$, and $\mathrm{S}$ in ash samples. The sampling position is indicated in each panel.

Figure 4 shows the relative composition of ashes. The effects of $\mathrm{HCl}$ and $\mathrm{SO}_{2}$ addition are most clearly seen in the chemical composition of the filter ash. The potassium content of the three types of ashes is similar in the base case. The potassium content of bed ash and secondary-cyclone ash is not strongly affected by $\mathrm{HCl}$ and $\mathrm{SO}_{2}$ addition, while $\mathrm{HCl}$ and/or $\mathrm{SO}_{2}$ addition doubles the potassium content of filter ash. The chlorine and sulfur fractions in the bed ash are close to zero in all cases, which means that potassium is retained in the bed by other species. The chlorine content of secondary-cyclone and bagfilter ashes is also low in the base case, but it increases strongly in the $\mathrm{Cl}$ and $\mathrm{Cl}+\mathrm{S}$ cases, especially in the filter, with chlorine fractions exceeding $10 \%$ of the total mass. There is sulfur in the fly ash, but the sulfur is more evenly distributed between secondary-cyclone ash and bag-filter ash than the chlorine. The sulfur fraction in secondary-cyclone ash is doubled when $\mathrm{SO}_{2}$ is added, and there is a strong increase in sulfur content in the filter ash in the $\mathrm{S}$ case.

Figure 5 shows $\mathrm{HCl}(\mathrm{g})$ and $\mathrm{SO}_{2}(\mathrm{~g})$ concentrations normalized to $6 \%$ oxygen level in dry flue gas at measurement positions $\mathrm{B}, \mathrm{E}$, and $\mathrm{G}$.

The concentrations are low and close to the detection limit $(1 \mathrm{ppm})$ in the base case. The $\mathrm{HCl}$ concentration increases upon $\mathrm{HCl}$ addition. In the $\mathrm{Cl}+\mathrm{S}$ case, there is a strong effect on the $\mathrm{HCl}$ concentration, which is higher at all of the measurement positions than in the $\mathrm{Cl}$ case. The $\mathrm{S}$ case also results in higher concentrations of $\mathrm{HCl}$ than in the base case. The $\mathrm{SO}_{2}$ concentration appears to be lowered upon $\mathrm{HCl}$ addition, as is clearly seen when comparing the $\mathrm{Cl}+\mathrm{S}$ and $\mathrm{S}$ cases. The measurement positions are placed in the same order as the flue gas passes them. The flue gas temperature is $\sim 800{ }^{\circ} \mathrm{C}$ at position $\mathrm{B}$ and falls to $\sim 160{ }^{\circ} \mathrm{C}$ at position $\mathrm{E}$, after passing the convection pass. Before position $\mathrm{G}$, situated just upstream of the stack, the flue 

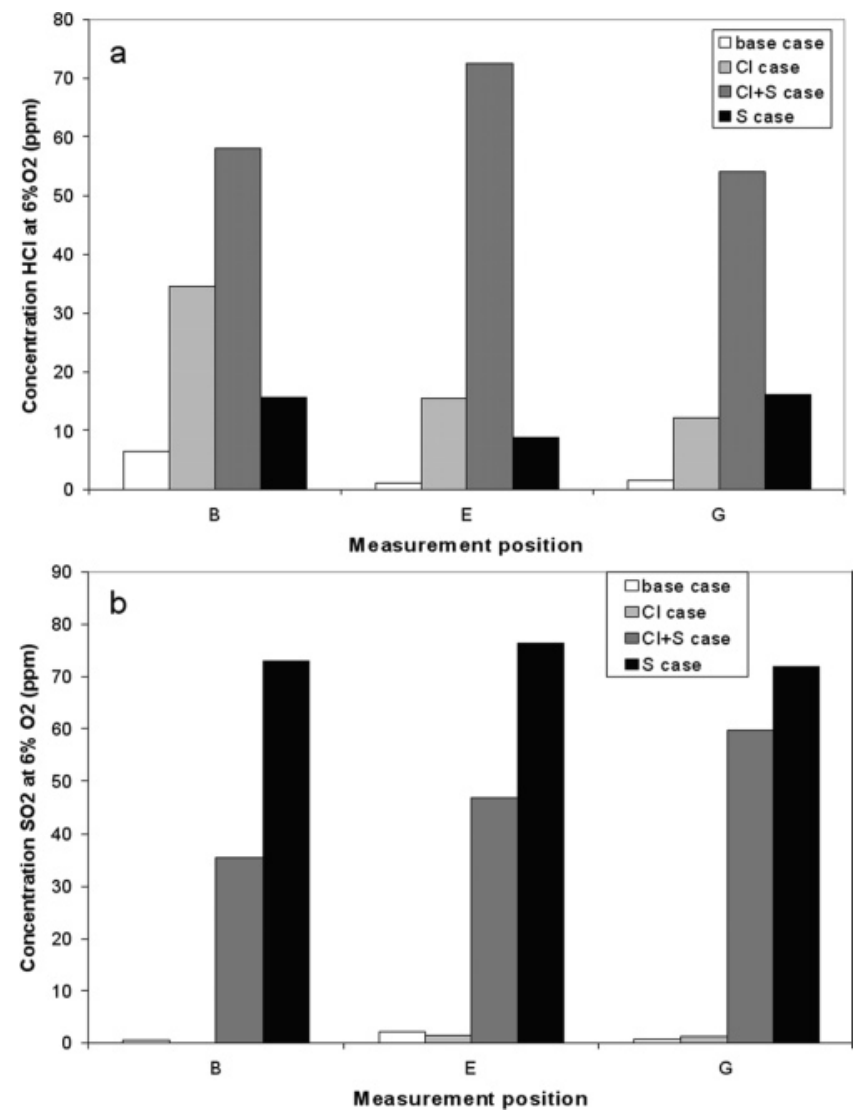

Figure 5. Flue gas concentrations at $6 \%$ oxygen of (a) $\mathrm{HCl}$ and (b) $\mathrm{SO}_{2}$ at measurements positions $\mathrm{B}, \mathrm{E}$, and $\mathrm{G}$. The flue gas temperature decreases from 800 to $160{ }^{\circ} \mathrm{C}$ on going from position $\mathrm{B}$ to $\mathrm{E}$.

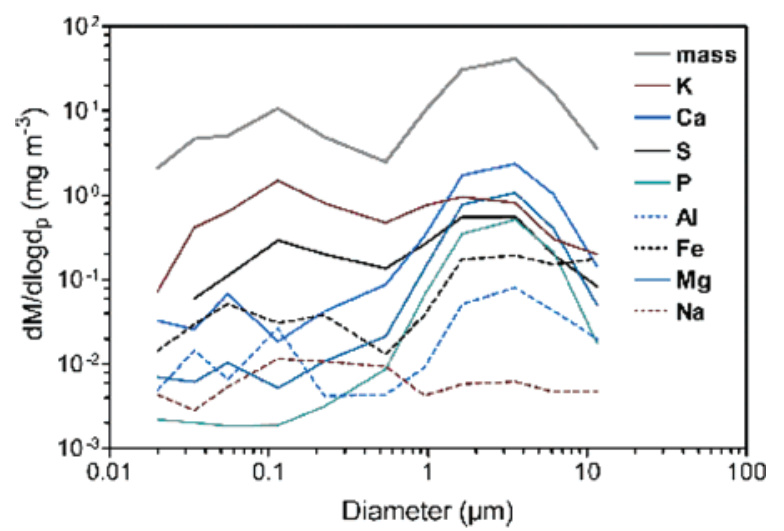

Figure 6. Particle mass size distributions for total mass and individual elements measured with an LPI at position F downstream of the secondary cyclone in a base case.

gas has passed the secondary cyclone that removes large fly ash particles and the bag filter that removes small fly ash particles. The $\mathrm{HCl}$ concentration decreases while moving from position $\mathrm{B}$ to $\mathrm{E}$, except in the $\mathrm{Cl}+\mathrm{S}$ case. In the latter case, the $\mathrm{SO}_{2}$ concentration also increases while the gas moves from B to $\mathrm{G}$.

Particle-Size Distributions in the Fly Ash. Particle mass size distributions for total mass and for selected elements are shown in Figure 6.

The distributions were measured at position $\mathrm{F}$ in the base case. The size distribution of total mass of collected particles shows a bimodal structure, which is often observed in the combustion of solid fuels. The fine-particle fraction $(<1 \mu \mathrm{m})$ is dominated by particles formed from volatilized elements that nucleate to form new particles or condense on existing particles

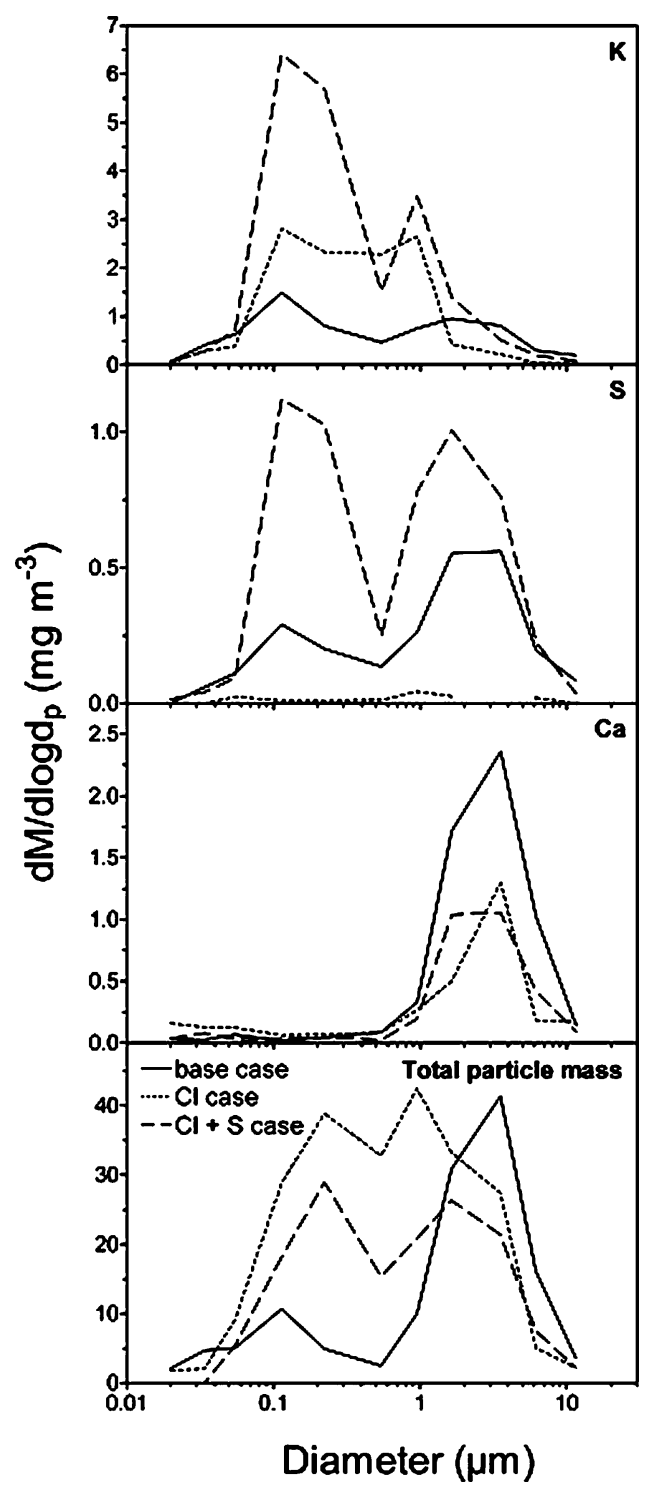

Figure 7. Particle mass size distributions of total mass and for $\mathrm{K}, \mathrm{S}$, and $\mathrm{Ca}$ in samples collected with the LPI at $160^{\circ} \mathrm{C}$. The measurements were performed at position $\mathrm{F}$ downstream of the secondary cyclone in the base, $\mathrm{Cl}$, and $\mathrm{Cl}+\mathrm{S}$ cases.

when the flue gas is cooled. The coarse particle fraction $(>1$ $\mu \mathrm{m})$ is dominated by ash components from the fuel that have remained in the solid (or liquid) phase during the combustion process. The distribution above $3 \mu \mathrm{m}$ is characterized by the capture efficiency of the cyclone connected to the sampling probe. Potassium and sodium are predominantly found in the fine particle fraction. The coarse-particle fraction consists mainly of nonvolatile elements such as calcium, magnesium, aluminum, iron, and phosphorus. Elements observed in the fine mode are also present in the coarse mode because of the condensation of gaseous components on the surface of large particles. There is sulfur both in the fine and coarse modes. The data indicate that sulfur-containing compounds partially are gaseous during combustion and partially remain in the solid phase. Chlorine was not included in the analysis, and the detected elements correspond to the mass fraction soluble in $1 \%$ nitric acid solution. The analysis thus excludes a fraction of elements bound to mixed silicates that are not dissolved by the acid solution.

Particle mass size distributions of total mass and for potassium, calcium, and sulfur are shown in Figures 7 and 8. The data in Figure 7 were obtained at measurement position $\mathrm{F}$, and Figure 8 shows data from position B. 


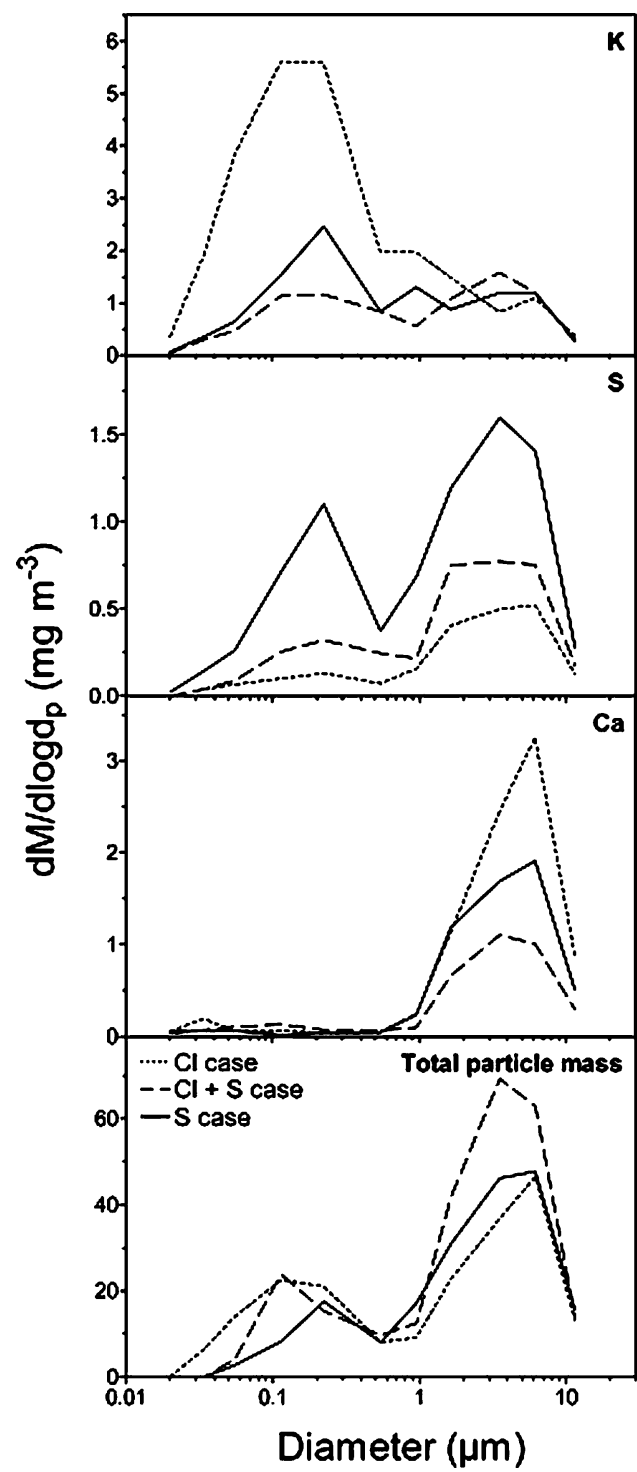

Figure 8. Particle mass size distributions for total mass and for $\mathrm{K}, \mathrm{S}$, and $\mathrm{Ca}$ in samples collected with the LPI at $800{ }^{\circ} \mathrm{C}$. The measurements were performed at position $\mathrm{B}$ downstream of the primary cyclone in the $\mathrm{Cl}, \mathrm{Cl}+\mathrm{S}$, and $\mathrm{S}$ cases.

The total mass of the fine-particle fraction increases considerably in the $\mathrm{Cl}$ and $\mathrm{Cl}+\mathrm{S}$ cases compared to that in the base case in Figure 7. The additions obviously result in larger concentrations of volatile compounds, which condense to form submicron particles when the flue gas is cooled. The concentration of coarse-mode particles does not change much during the addition of $\mathrm{HCl}$ and $\mathrm{SO}_{2}$. The small changes observed can be attributed to minor fluctuations in boiler operation. The potassium data show that the higher particle mass in the $\mathrm{Cl}$ and $\mathrm{Cl}$ $+\mathrm{S}$ cases than in the base case to a large extent is related to the increased concentration of potassium compounds. The sulfur concentrations increase considerably in both the fine- and coarseparticle modes for the $\mathrm{Cl}+\mathrm{S}$ case compared to the $\mathrm{Cl}$ case. The calcium mass size distribution is qualitatively similar in the three cases. Calcium is almost exclusively found in the coarse fraction, irrespective of the additions made to the fuel. Therefore, it can be concluded that the coarse fly ash component is not strongly influenced by changes in potassium, chlorine, and sulfur concentrations. Changes in the surface properties of supermicron particles can, however, not be excluded, since some of the material producing small particles condenses on the surface of larger particles.

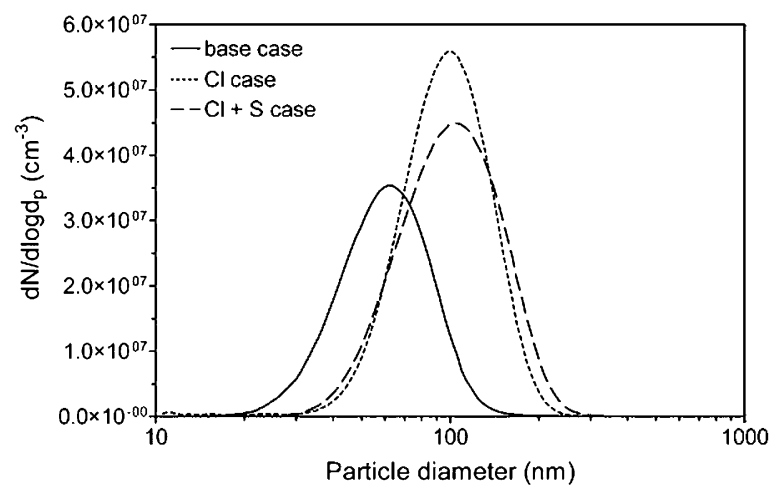

Figure 9. Particle number size distributions measured with SMPS at position $\mathrm{F}$ downstream of the secondary cyclone in the base, $\mathrm{Cl}$, and $\mathrm{Cl}+\mathrm{S}$ cases.

Table 4. Main Phases Found on the 304L Samples by XRD ${ }^{a}$

\begin{tabular}{llccccc}
\hline & $\begin{array}{c}\text { exposure } \\
\text { time }\end{array}$ & $\mathrm{KCl}$ & $\mathrm{K}_{2} \mathrm{SO}_{4}$ & $\mathrm{CaCO}_{3}$ & $\mathrm{~K}_{2} \mathrm{Ca}_{2}\left(\mathrm{SO}_{4}\right)_{3}$ & $\begin{array}{c}\text { steel } \\
\text { signal }\end{array}$ \\
\hline base case & $15 \mathrm{~min}$ & & & & & $\mathrm{~S}$ \\
& $1 \mathrm{~h}$ & & $\mathrm{~W}$ & & $\mathrm{~W}$ & $\mathrm{~S}$ \\
& $12 \mathrm{~h}$ & & $\mathrm{M}$ & & $\mathrm{M}$ & $\mathrm{S}$ \\
$\mathrm{Cl}$ case & $15 \mathrm{~min}$ & $\mathrm{M}$ & & & & $\mathrm{S}$ \\
& $1 \mathrm{~h}$ & $\mathrm{~S}$ & & & & $\mathrm{M}$ \\
& $6 \mathrm{~h}$ & $\mathrm{~S}$ & & $\mathrm{~W}$ & & \\
$\mathrm{~S}$ case & $1 \mathrm{~h}$ & & $\mathrm{M}$ & & & $\mathrm{S}$ \\
& $6 \mathrm{~h}$ & & $\mathrm{~S}$ & & $\mathrm{M}$ & $\mathrm{S}$ \\
$\mathrm{Cl}+\mathrm{S}$ case & $15 \mathrm{~min}$ & $\mathrm{~W}$ & $\mathrm{~W}$ & & & $\mathrm{~S}$ \\
& $1 \mathrm{~h}$ & $\mathrm{~W}$ & $\mathrm{~W}$ & & & $\mathrm{~S}$ \\
& $6 \mathrm{~h}$ & $\mathrm{~S}$ & $\mathrm{M}$ & & $\mathrm{W}$ &
\end{tabular}

${ }^{a} \mathrm{~W}, \mathrm{M}$, and $\mathrm{S}$ denote weak, medium, and strong signals, respectively, in the XRD analysis.

Figure 8 shows data from position B. At the high temperature $\left(800^{\circ} \mathrm{C}\right)$, some of the gaseous components condense as the gas is cooled in the probe. The condensation leads to formation and growth of submicron particles in suspension and deposition on available surfaces. Such effects have not been quantified in detail. The total mass and calcium mass size distributions are similar for the displayed $\mathrm{Cl}, \mathrm{Cl}+\mathrm{S}$, and $\mathrm{S}$ cases, and the distributions are also qualitatively comparable to the data from measurement point $\mathrm{F}$ (Figure 7). The total mass of the coarsemode particles is somewhat higher at position $\mathrm{B}$ than in position $\mathrm{F}$, which is reasonable as some of the large particles are removed by the secondary cyclone. The sulfur mass concentrations are highest in the $\mathrm{S}$ case, indicating that the added $\mathrm{SO}_{2}$ is efficiently transformed to particulate sulfur. The potassium concentration in fine-mode particles is particularly pronounced in the $\mathrm{Cl}$ case; the added $\mathrm{HCl}$ enhances the formation of potassium compounds from the fuel.

Number size distributions of submicron particles in the flue gas are shown in Figure 9.

Sampling at position $\mathrm{F}$ in the base case, the $\mathrm{Cl}$ case, and the $\mathrm{Cl}+\mathrm{S}$ case shows that the number concentration of the fineparticle fraction increases and shifts to larger particle sizes in the $\mathrm{Cl}$ and $\mathrm{Cl}+\mathrm{S}$ cases than in the base case. The number size distribution shifts from a peak $\sim 60 \mathrm{~nm}$ in the base case to a position $\sim 100 \mathrm{~nm}$ in the addition cases, corresponding to an increase in particle mass of approximately a factor of 5. This is in good agreement with the increase in mass of the fine-particle mode in the $\mathrm{Cl}$ and $\mathrm{Cl}+\mathrm{S}$ cases (Figure 7). Similar tendencies have been reported from measurements with other methods. ${ }^{25}$

Initial Deposit Formation and Corrosion. Visual inspection of the $304 \mathrm{~L}$ rings after 15 min exposure showed that the surface

(25) Åmand, L.-E.; Leckner, B.; Eskilsson, D.; Tullin, C. Energy Fuels 2006, 20, 1001-1007. 

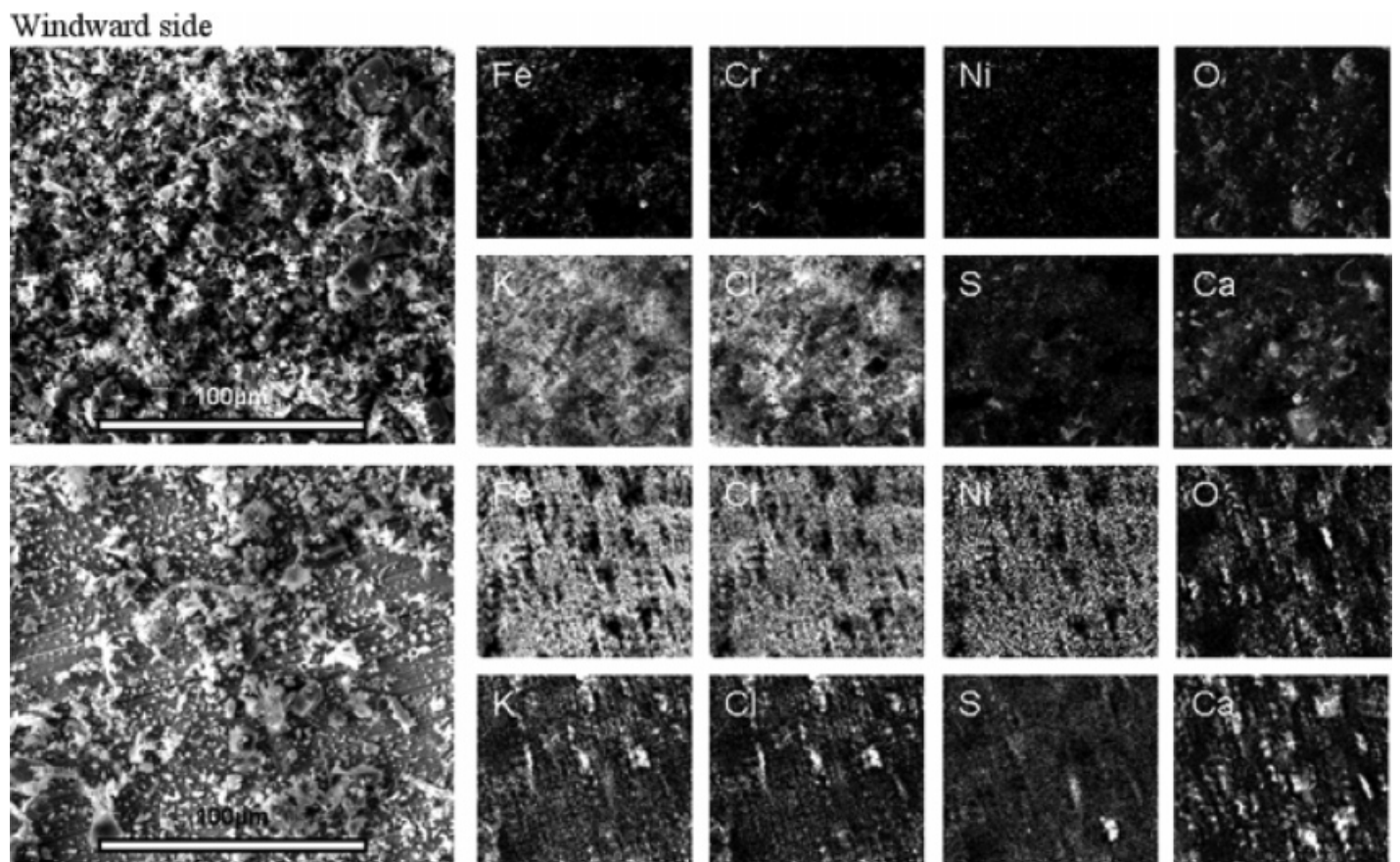

Leeward side
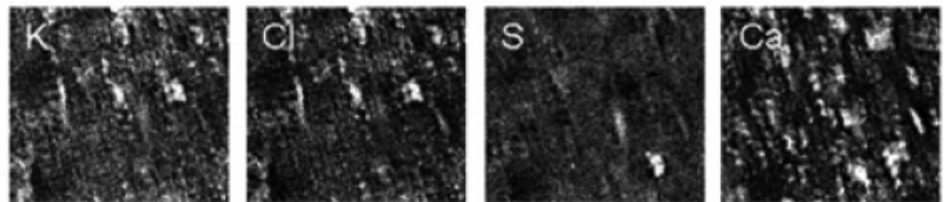

Figure 10. ESEM and EDX qualitative maps of the sample surface of 304 after $1 \mathrm{~h}$ exposure in the $\mathrm{Cl}$ case.
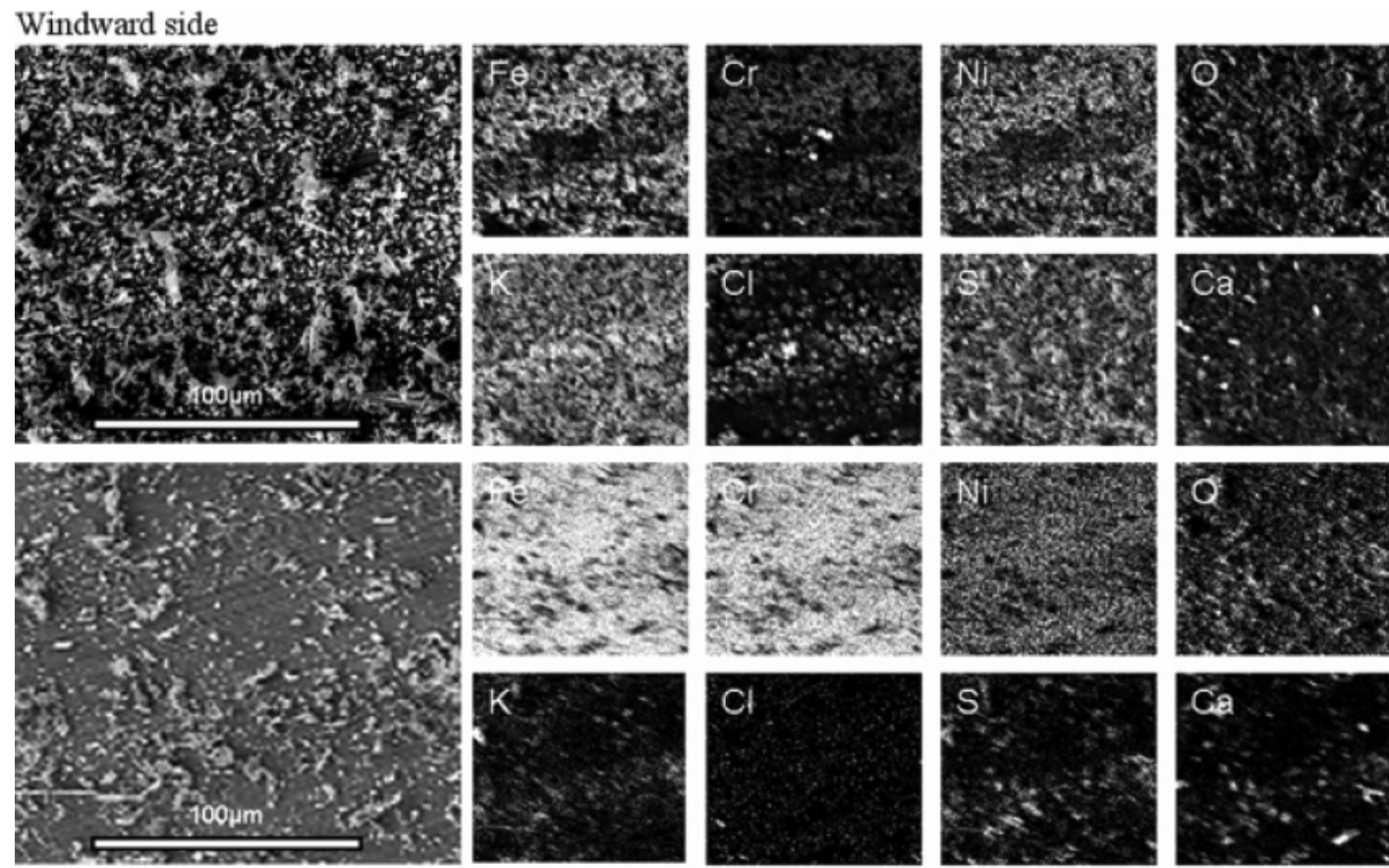

Leeward side
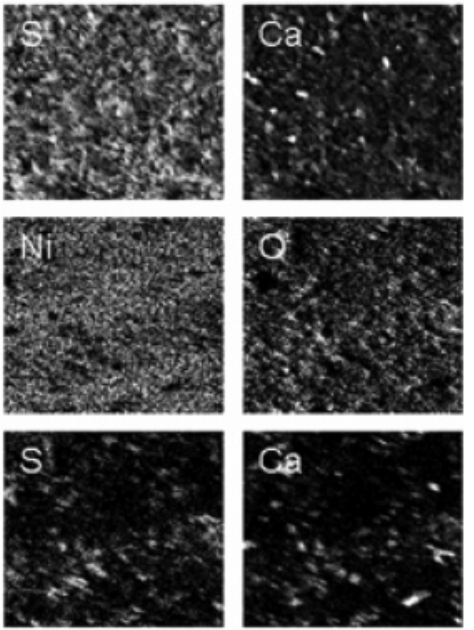

Figure 11. ESEM and EDX qualitative maps of the sample surface of 304 after $1 \mathrm{~h}$ exposure in the $\mathrm{Cl}+\mathrm{S}$ case.

had a gold/bronze interference color, with a dull surface finish, originating from deposited ash particles. Obviously, the surface was covered by an oxide film in the $100 \mathrm{~nm}$ range and by ash particles of micrometer size. After exposure for $1 \mathrm{~h}$, a clearly visible deposit layer of white ash had formed, especially on the windward side. A metallic luster could still be seen on the leeward side. After $12 \mathrm{~h}$, a white ash deposit completely covered the surface, with the layer being somewhat thicker on the windward side. The deposits in different cases appeared visually similar. The composition of the exposed samples analyzed by GI XRD is shown in Table 4 . In the base case, $\mathrm{K}_{2} \mathrm{SO}_{4}$ and $\mathrm{K}_{2} \mathrm{Ca}_{2}\left(\mathrm{SO}_{4}\right)_{3}$ were the only phases detected in the ash deposit. The deposit formed in the $\mathrm{S}$ case had a similar composition as in the base case. In the $\mathrm{Cl}$ case, the deposit was dominated by $\mathrm{KCl}$ together with traces of $\mathrm{CaCO}_{3}$. In the $\mathrm{Cl}+\mathrm{S}$ case, the deposit consisted of a mixture of $\mathrm{KCl}$ and $\mathrm{K}_{2} \mathrm{SO}_{4}$. As expected, the samples exposed for 15 min showed peaks from the steel substrate with strong intensity diffraction. After $6 \mathrm{~h}$ exposure, diffraction from the steel substrate was detected in the base case and in the sulfur case but not in the $\mathrm{Cl}$ and the $\mathrm{Cl}+\mathrm{S}$ cases, indicating that more deposits had formed in those environments.

Figures 10 and 11 show ESEM plan views and qualitative EDX maps of sample surfaces exposed at $500{ }^{\circ} \mathrm{C}$ for $1 \mathrm{~h}$ in the $\mathrm{Cl}$ and $\mathrm{Cl}+\mathrm{S}$ cases, respectively.

The elements iron, chromium, and nickel in steel are shown in the upper row of the EDX map of Figure 10 and 11. A high 
intensity of these elements means that the area has little ash deposits. The lower row shows the ash elements potassium, sulfur, chlorine, and calcium. Also, silicon and aluminum appear sporadically, and traces of magnesium, sodium, and titanium were detected. Figure 10 illustrates the deposit formed after 1 $\mathrm{h}$ in the $\mathrm{Cl}$ case. The upper map is the situation on the windward side. The low levels of iron, chromium, and nickel prove that most of the steel surface was covered by the deposit. Strong signals for potassium and chlorine indicate that the deposit consists of $\mathrm{KCl}$. In addition, small amounts of sulfur, calcium, and oxygen were observed. The deposit formed on the leeward side was far thinner (lower maps in Figure 10), as revealed by the strong signals for iron, chromium, and nickel from a bare steel surface. The presence of deposited particles on the leeward side is shown by a sporadic appearance of potassium, chlorine, sulfur, calcium, and oxygen. Smaller amounts of deposits appear to have formed after $1 \mathrm{~h}$ in the $\mathrm{Cl}+\mathrm{S}$ case than in the $\mathrm{Cl}$ case (see Figure 11). The relatively thick deposit on the windward side is dominated by potassium, sulfur, chlorine, and oxygen. In addition, signals from the steel substrate appear. The small amount of deposits on the leeward side is dominated by sulfur and calcium.

The EDX maps were further analyzed by principal component analysis (PCA), ${ }^{26}$ trying to explain the covariance structure of data by means of a small number of components. These components are linear combinations of the original variables and often allow for an interpretation and a better understanding of the different sources of variation. The method requires no a priori knowledge about the number and types of components. In the present analysis, each pixel on the EDX maps was treated as one measurement, resulting in a total of $100 \times 100$ measurements with different elemental compositions. The analysis included a VARIMAX rotation of the principalcomponent loading matrix. ${ }^{26}$ The results from the PCA analyses are summarized in Table 5 for the $\mathrm{Cl}$ case and in Table 6 for the $\mathrm{Cl}+\mathrm{S}$ case. The tables describe the components identified in each analysis, with decreasing significance of the components from left to right. The rightmost column in Tables 5 and 6 shows the communalities of the analysis that express the percentage of each element's variability that was explained by the results. The last line gives the magnitude (eigenvalue) of each component, which indicates the importance of the component for the total solution. The number of analyzed elements varied from case to case. In each component, the values given for the elements are their correlation with other elements in that component. Elements with matrix values near +1 in the same component are highly correlated, elements with values near -1 are anticorrelated, and elements with values near zero are not correlated.

The matrix values of each component point at the origin of the associated signals, and when possible, components are identified with different sources (see first rows in each subsection of Tables 5 and 6). For example, the first component in the leeward side data in Table 5 has high values for sodium, oxygen, aluminum, calcium, magnesium, phosphorus, and silicon. These elements are commonly present in fly ash, and the component is identified as "fly ash". The second component shows high values for chromium, iron, and nickel (and the minor element titanium) and should originate from the surface of the steel substrate. A steel component is present in all cases listed in Tables 5 and 6. Fly ash components are also observed, and sometimes sulfur and potassium are found together with the

(26) Jolliffe, I. T. Principal component analysis, second ed.; Springer: New York, 2002.
Table 5. Principal Component Analysis of Deposits on Alloy 304L after Exposure in the Cl Case (The Different Components are Indicated by Their Attributed Origin)

\begin{tabular}{|c|c|c|c|c|c|}
\hline $\begin{array}{l}\text { leeward } \\
\text { side }\end{array}$ & fly ash & steel & $\mathrm{KCl}$ & $\mathrm{S}$ and $\mathrm{P}$ & $\begin{array}{l}\text { commun- } \\
\text { alities }\end{array}$ \\
\hline $\mathrm{Na}$ & 0.744 & 0.046 & 0.176 & -0.004 & 0.669 \\
\hline $\mathrm{O}$ & 0.847 & -0.137 & -0.128 & 0.113 & 0.801 \\
\hline $\mathrm{Al}$ & 0.852 & 0.012 & 0.009 & -0.056 & 0.687 \\
\hline $\mathrm{Ca}$ & 0.463 & -0.506 & -0.013 & 0.207 & 0.741 \\
\hline $\mathrm{Cl}$ & -0.004 & -0.150 & 0.790 & 0.147 & 0.853 \\
\hline $\mathrm{Cr}$ & -0.112 & 0.817 & -0.151 & 0.071 & 0.829 \\
\hline $\mathrm{Fe}$ & -0.162 & 0.802 & -0.195 & 0.055 & 0.891 \\
\hline K & -0.003 & -0.258 & 0.754 & 0.140 & 0.889 \\
\hline $\mathrm{Mg}$ & 0.582 & -0.219 & 0.043 & 0.271 & 0.723 \\
\hline $\mathrm{Ni}$ & -0.038 & 0.756 & -0.160 & 0.020 & 0.697 \\
\hline $\mathrm{S}$ & 0.016 & 0.027 & 0.061 & 0.862 & 0.799 \\
\hline $\mathrm{P}$ & 0.465 & 0.013 & -0.006 & 0.483 & 0.635 \\
\hline $\mathrm{Si}$ & 0.729 & -0.287 & 0.213 & -0.294 & 0.773 \\
\hline $\mathrm{Ti}$ & 0.286 & 0.846 & 0.544 & -0.249 & 0.706 \\
\hline magnitude & 6.906 & 1.992 & 1.044 & 0.751 & \\
\hline $\begin{array}{l}\text { windward } \\
\text { side }\end{array}$ & steel & $\mathrm{KCl}+\mathrm{S}$ & $\begin{array}{c}\text { fly } \\
\text { ash1 }\end{array}$ & $\begin{array}{c}\text { fly } \\
\text { ash } 2\end{array}$ & $\begin{array}{l}\text { commun- } \\
\text { alities }\end{array}$ \\
\hline $\mathrm{Ca}$ & -0.382 & -0.475 & 0.603 & -0.024 & 0.813 \\
\hline $\mathrm{Cl}$ & $-3.482 \mathrm{E}-4$ & 0.940 & -0.157 & -0.023 & 0.855 \\
\hline $\mathrm{Fe}$ & 0.815 & -0.101 & -0.034 & 0.065 & 0.788 \\
\hline $\mathrm{K}$ & -0.079 & 0.930 & -0.023 & -0.029 & 0.906 \\
\hline $\mathrm{Mg}$ & $-7.923 \mathrm{E}-5$ & 0.021 & 0.852 & -0.004 & 0.735 \\
\hline $\mathrm{Ni}$ & 1.023 & -0.030 & 0.311 & -0.258 & 0.690 \\
\hline $\mathrm{Mn}$ & -0.091 & -0.005 & 0.036 & 0.987 & 0.922 \\
\hline $\mathrm{O}$ & 0.224 & 0.063 & 0.971 & 0.022 & 0.755 \\
\hline S & 0.149 & 0.524 & 0.460 & 0.106 & 0.478 \\
\hline $\mathrm{Cr}$ & 0.668 & 0.037 & -0.115 & 0.227 & 0.691 \\
\hline magnitude & 3.525 & 2.077 & 1.186 & 0.845 & \\
\hline
\end{tabular}

Table 6. Principal Component Analysis of Elements on Alloy 304L after Exposure in the $\mathrm{Cl}+\mathrm{S}$ Case (The Different Components are Indicated by Their Attributed Origin)

\begin{tabular}{lcrrrrr}
\hline $\begin{array}{c}\text { leeward } \\
\text { side }\end{array}$ & steel & $\begin{array}{c}\text { fly } \\
\text { ash 1 }\end{array}$ & \multicolumn{1}{c}{$\mathrm{Cl}$} & $\begin{array}{c}\text { fly } \\
\text { ash 2 }\end{array}$ & $\mathrm{K}_{2} \mathrm{SO}_{4}$ & $\begin{array}{c}\text { commun } \\
\text { alities }\end{array}$ \\
\hline $\mathrm{Ca}$ & -0.736 & 0.271 & 0.005 & 0.106 & 0.026 & 0.751 \\
$\mathrm{Cl}$ & 0.031 & 0.007 & 0.987 & 0.001 & 0.029 & 0.982 \\
$\mathrm{Cr}$ & 0.717 & 0.016 & 0.090 & 0.068 & -0.246 & 0.698 \\
$\mathrm{Fe}$ & 0.735 & -0.054 & 0.077 & 0.029 & -0.277 & 0.791 \\
$\mathrm{~K}$ & -0.050 & 0.002 & -0.013 & 0.016 & 0.865 & 0.787 \\
$\mathrm{Mg}$ & -0.418 & 0.436 & 0.051 & 0.317 & -0.044 & 0.597 \\
$\mathrm{Na}$ & 0.021 & -0.038 & -0.013 & 0.945 & 0.045 & 0.893 \\
$\mathrm{Ni}$ & 0.790 & 0.115 & -0.066 & -0.008 & 0.056 & 0.572 \\
$\mathrm{O}$ & $-4.577 \mathrm{E}-5$ & 0.388 & 0.098 & 0.301 & 0.432 & 0.601 \\
$\mathrm{P}$ & 0.043 & 0.922 & -0.024 & -0.096 & 0.032 & 0.822 \\
$\mathrm{~S}$ & -0.242 & 0.016 & 0.040 & 0.017 & 0.731 & 0.732 \\
magnitude & 4.248 & 1.384 & 0.945 & 0.880 & 0.771 & \\
& & & & & &
\end{tabular}

\begin{tabular}{lrrcc}
\hline $\begin{array}{c}\text { windward } \\
\text { side }\end{array}$ & fly ash & \multicolumn{1}{c}{$\mathrm{KCl}$} & steel & $\begin{array}{c}\text { commun- } \\
\text { alities }\end{array}$ \\
\hline $\mathrm{Al}$ & 0.649 & 0.160 & $8.010 \mathrm{E}-6$ & 0.571 \\
$\mathrm{Ca}$ & 0.345 & -0.421 & -0.482 & 0.789 \\
$\mathrm{Cl}$ & -0.002 & 0.827 & 0.003 & 0.730 \\
$\mathrm{Cr}$ & 0.053 & 0.008 & 0.819 & 0.863 \\
$\mathrm{Fe}$ & -0.008 & -0.069 & 0.797 & 0.908 \\
$\mathrm{~K}$ & 0.433 & 0.774 & -0.033 & 0.886 \\
$\mathrm{Mg}$ & 0.654 & -0.198 & -0.176 & 0.786 \\
$\mathrm{Na}$ & 0.759 & 0.249 & 0.113 & 0.701 \\
$\mathrm{Ni}$ & 0.020 & -0.036 & 0.768 & 0.802 \\
$\mathrm{O}$ & 0.773 & -0.063 & -0.022 & 0.816 \\
$\mathrm{~S}$ & 0.657 & 0.240 & 0.002 & 0.611 \\
$\mathrm{magnitude}$ & 5.325 & 1.630 & 1.506 &
\end{tabular}

other fly ash elements. More than one fly ash component is occasionally identified, and the coarse particles may be heterogeneous in composition. Since only a small number of large fly ash particles may have been collected on the analyzed surface, the results could also be biased by statistics. In the $\mathrm{Cl}$ case, potassium and chlorine are strongly correlated both on the windward and leeward sides of the probe, and $\mathrm{KCl}$ is 


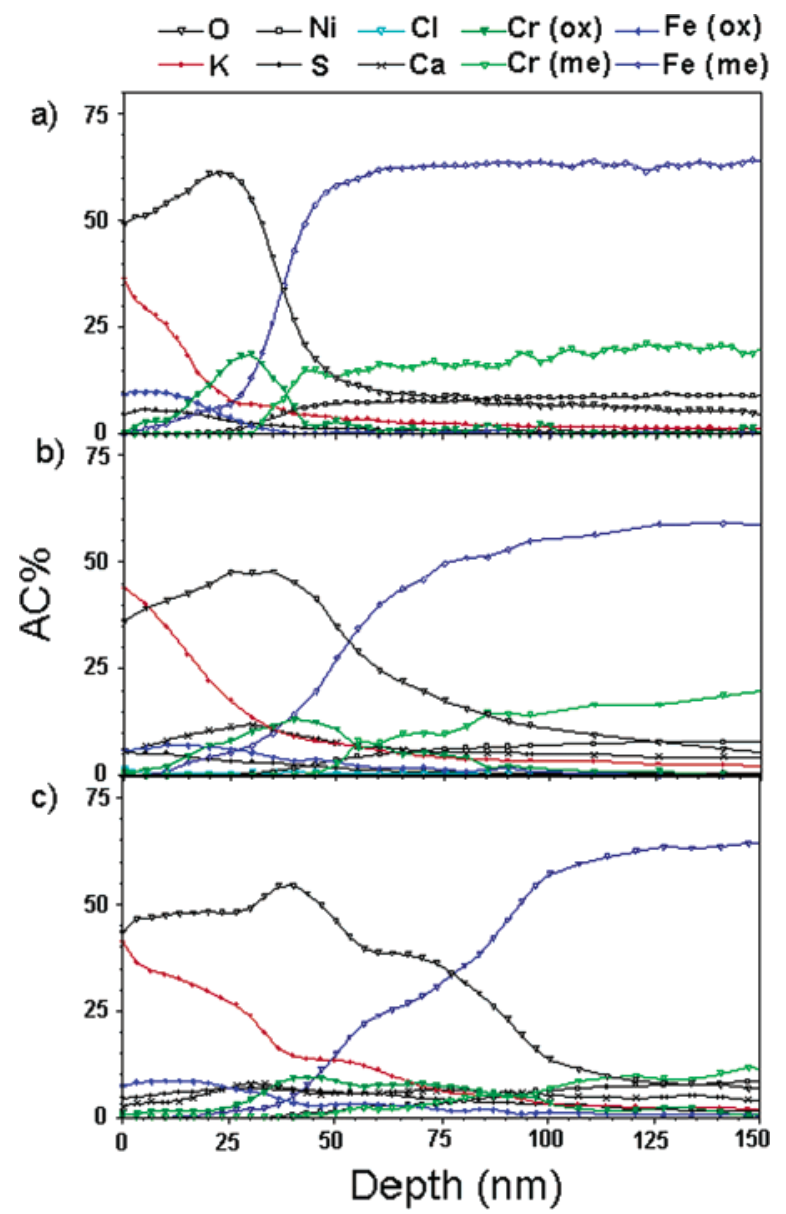

Figure 12. AES-depth profiles of the thin oxide formed on the leeward side of the 304 samples after $1 \mathrm{~h}$ during (a) base case, (b) $\mathrm{Cl}$ case, and (c) $\mathrm{Cl}+\mathrm{S}$ case.

obviously the main potassium compound (see component marked $\mathrm{KCl}$ in Table 5). Potassium and chlorine are not associated with the elements related to fly ash. Sulfur is found together with both $\mathrm{KCl}$ and fly ash on the windward side, while it is not related to $\mathrm{KCl}$ on the leeward side. In the $\mathrm{Cl}+\mathrm{S}$ case in Table 6, potassium and chlorine are seen together with sodium and sulfur on the windward side, probably pointing at the existence of mixed alkali chlorides and sulfates. Sulfur also exists in the fly ash phase, deposited on the windward side. On the leeward side, there is potassium instead together with sulfur and oxygen, and most likely, $\mathrm{K}_{2} \mathrm{SO}_{4}$ has been deposited on the surface. The existence of low chlorine concentrations on the leeward side is not correlated with other elements. The conditions with respect to potassium, chlorine, and sulfur chemistries are rather different on the windward and leeward sides of the deposit probe, pointing to an effect of gas and particle transport to the two sides. Fly ash is mainly present on the windward side, and therefore, this deposition is likely to have occurred by impaction. ${ }^{3}$ Potassium is not associated with fly ash in any of the cases. The presence of $\mathrm{KCl}$ on the leeward side in the $\mathrm{Cl}$ case suggests direct condensation on the steel or thermophoresis of homogeneously formed $\mathrm{KCl}$ particles. ${ }^{3}$ Condensation of $\mathrm{KCl}$ has been reported in other studies. ${ }^{1,4,22}$ The absence of $\mathrm{KCl}$ on the leeward side in the $\mathrm{Cl}+\mathrm{S}$ case suggests that potassium mainly condenses as sulfate.

The corroded sample surface was characterized by SAM depth profiling. Figure 12 shows Auger depth profiles collected on the leeward side of samples exposed for $1 \mathrm{~h}$ in different environments.
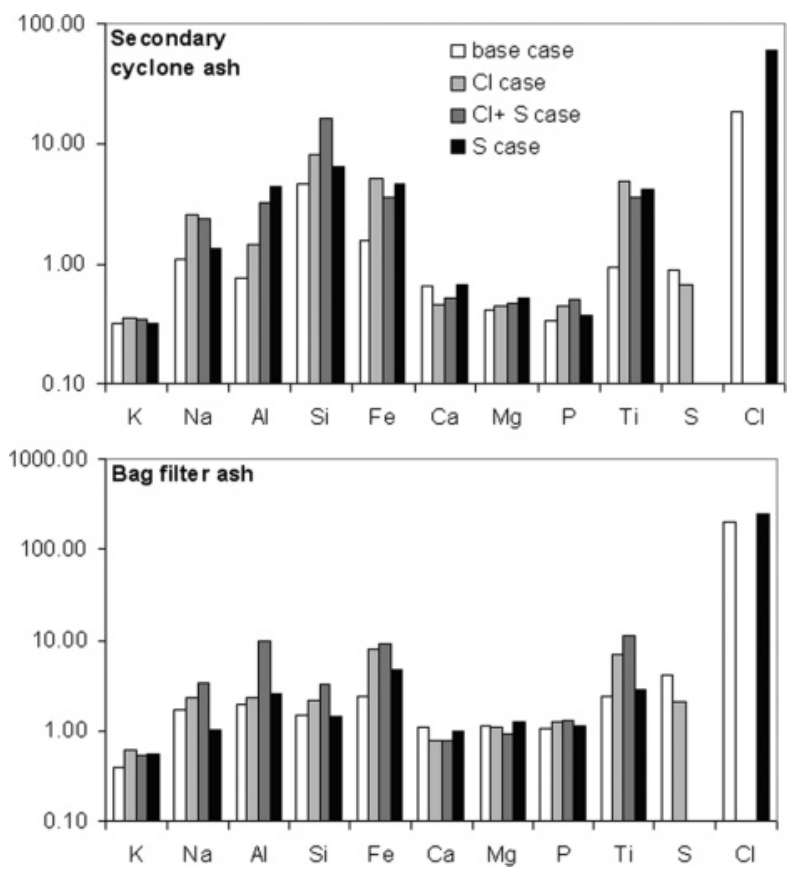

Figure 13. Elemental enrichment factors of analyzed elements in secondary cyclone and bag filter ash. The ash composition (wt \% of dry ash, see Table 1) for wood chips and pellets mixtures was the reference material.

The oxide is $50-100 \mathrm{~nm}$ thick and has similar elemental composition in the different environments. It is dominated by iron and chromium oxide, with the bottom part being enriched in chromium. The only element originating from the ash deposit that is present in significant amounts is potassium, found in the outer part of the oxide layer. There were also small amounts of calcium and sulfur in the outer part of the oxide layer, but the occurrence and concentration of these elements are more erratic than those of potassium. No chlorine was detected in the oxide, not even in the $\mathrm{Cl}$ and $\mathrm{Cl}+\mathrm{S}$ cases (parts $\mathrm{b}$ and $\mathrm{c}$ of Figure 12 , respectively).

\section{Comments on the Results}

As estimated from ash flows and compositions, $30-60 \%$ of the potassium became strongly bound to the bed material and left the CFB with bed ash, 5-15\% left the system with secondary cyclone ash, and 10-25\% left with bag-filter ash. The total potassium output was only $60-85 \%$ of the input during the experiments. If it is assumed that the potassium concentration in the bed was stable during each experiment, $15-40 \%$ of the potassium would have been deposited on the heat-transfer surfaces of the boiler, corresponding to $0.2-0.6 \mathrm{~kg} \mathrm{~h}^{-1}$ of potassium. This estimate is uncertain since the detailed deposition on the tube walls is unknown. In order to investigate the loss of potassium to the walls, enrichment factors (EFs) were calculated for different fuel-ash elements. An EF is the ratio of the concentration of an element in the ash sample to the concentration of the same element in the fuel ash (see Table 1). EFs are shown in Figure 13.

Bed ash has been excluded because of the diluting effect of sand. Also the secondary-cyclone ash is probably affected by silicon from the bed sand, which results in a high EF for silicon and low EFs for the other elements. Chlorine and sulfur have been excluded in the cases in which they were added. Major fly ash elements, like calcium, magnesium, and phosphorus that remain in the solid phase throughout the combustion process, display similar EFs in the different ashes and cases. Losses of 
these elements are relatively small in the system. In the secondary-cyclone and bag-filter ashes, potassium has a lower EF than any of the other elements. This is a strong indication that potassium is lost during transport from the fluidized bed toward the bag filter. If it is assumed that calcium is not lost in the system and the EFs of calcium and potassium are compared, the "missing potassium" in the secondary-cyclone and bag-filter ashes can be calculated to be $0.2-0.6 \mathrm{~kg} \mathrm{~h}^{-1}$. This estimate is in excellent agreement with the loss of potassium calculated above, based on ash flows and compositions, and it is concluded that $15-40 \%$ of the potassium initially deposits on the inner walls of the boiler during the conversion process.

Although ash may pile up in many locations, for this crude estimate it is sufficient to consider the tube and wall area of the convection section and economizer, which is $\sim 500 \mathrm{~m}^{2}$. With a potassium deposition rate of $0.4 \mathrm{~kg} \mathrm{~h}^{-1}$, a layer of potassium salt would then build up with an average deposition rate of $\sim 2$ $\mu \mathrm{m} \mathrm{h}^{-1}$. This is in fair agreement with the deposits observed on the steel rings. Most of the potassium is found in the form of salts on top of the steel surface (Figures 10 and 11), and a very small fraction intercalates the topmost layer of the steel (Figure 12).

Both flue gas chemistry and properties of fly ash particles in the superheater region of the CFB boiler are affected by adding $\mathrm{SO}_{2}$ and $\mathrm{HCl}$ to the fuel; in particular, this affects the physical and chemical state of the potassium. The fuels of the present study have low chlorine concentrations compared to their potassium concentrations. Therefore, it is likely that initial potassium release takes place as $\mathrm{KOH}$ or other potassiumcontaining compounds rather than as $\mathrm{KCl} .{ }^{14} \mathrm{KOH}$ may subsequently react to form another more stable potassium compound depending on the concentrations of other species. The potassium compounds may adsorb on bed particles and form stable potassium silicates or potassium alumino silicates. ${ }^{15} \mathrm{KOH}(\mathrm{g})$ readily reacts with $\mathrm{HCl}(\mathrm{g})$ to form $\mathrm{KCl}(\mathrm{g}) . \mathrm{K}_{2} \mathrm{SO}_{4}(\mathrm{~g})$ nucleates to form new particles at a temperature of $\sim 800{ }^{\circ} \mathrm{C}$, while $\mathrm{KCl}$ (g) condenses at $500-600{ }^{\circ} \mathrm{C}$. A major part of the potassium is captured in the bed material, presumably forming silicate. Addition of $\mathrm{HCl}$ and/or $\mathrm{SO}_{2}$ increases the potassium flow in the secondary-cyclone ash and especially in the filter ash. In the $\mathrm{Cl}$ case, the chlorine flow increases significantly in the bagfilter ash. In the $\mathrm{Cl}+\mathrm{S}$ case, the chlorine flow shifts from the filter to the flue gas, suggesting a reaction scheme where chlorine and sulfur competes to react with potassium. This scheme has been reported before. ${ }^{20,22,27,28}$ The potassium fraction in the ashes appears not to be significantly altered by the additions, but this may be due to lack of accuracy in measuring such small ash flows. However, the association between potassium and sulfur is seen in the change in particle composition (Figure 7) and the deposit analysis (Figures 10 and 11). In the $\mathrm{S}$ case, the chlorine concentrations are higher in the fly ash and the flue gas than in the base case, despite the same input flow. Despite steam sooting before each experiment, it is impossible to clean every surface area. Therefore, since no chlorine is found in the bed material, this can only be attributed to memory effects, i.e., reactions between sulfur and deposits already present in the boiler. In the $\mathrm{S}$ case, the sulfur flow in fly ash and flue gas increases. Compared to this increase, the sulfur flow decreases sharply in the filter ash in the $\mathrm{Cl}+\mathrm{S}$ case. This could be explained by the competitive reaction between chlorine, sulfur, and potassium.

(27) Robinson, A. L.; Junker, H.; Baxter, L. L. Energy Fuels 2002, 16, 343-355.

(28) Skrifvars, B.-J.; Backman, R.; Hupa, M.; Sfiris, G.; Åbyhammar, T.; Lyngfelt, A. Fuel 1998, 77, 65-70.
In the base case, potassium release from the bed was limited, and the fine-particle concentrations were relatively low in the flue gas. The gas-phase concentrations of $\mathrm{HCl}$ and $\mathrm{SO}_{2}$ were low in this case, and only a small fraction of potassium compounds could react to form potassium chloride or sulfate. $\mathrm{HCl}$ addition increased the fine-particle concentrations significantly, since the alkali species released from the fuel react with $\mathrm{HCl}$ to form $\mathrm{KCl}$, which, to a large extent, escaped from the bed. According to the PCA analysis, the particles reach the deposit probe. In the $\mathrm{S}$ case, more potassium was released from the bed and higher concentrations of fine particles were present than in the base case. Formation of sulfate is often rate limited by the formation of $\mathrm{SO}_{3}(\mathrm{~g})$ from $\mathrm{SO}_{2}(\mathrm{~g}){ }^{29}$ The present results, however, indicate that availability of $\mathrm{SO}_{3}(\mathrm{~g})$ did not severely restrict reaction to sulfate in the $\mathrm{S}$ case. In the $\mathrm{Cl}+\mathrm{S}$ case, chlorine and sulfur compete to react with potassium. Addition of $\mathrm{HCl}$ and $\mathrm{SO}_{2}$ affects the overall reaction,

$$
\begin{array}{r}
4 \mathrm{KCl}(\mathrm{s})+2 \mathrm{SO}_{2}(\mathrm{~g})+2 \mathrm{H}_{2} \mathrm{O}(\mathrm{g})+\mathrm{O}_{2}(\mathrm{~g}) \leftrightarrow \\
\mathrm{K}_{2} \mathrm{SO}_{4}(\mathrm{~s})+4 \mathrm{HCl}(\mathrm{g}),
\end{array}
$$

and under the conditions employed here, the $\mathrm{Cl}+\mathrm{S}$ case resulted in $\mathrm{KCl}$ and $\mathrm{K}_{2} \mathrm{SO}_{4}$.

In the base case, $\mathrm{K}_{2} \mathrm{SO}_{4}$ (s) deposits on the corrosion probes. When $\mathrm{HCl}$ is added to the fuel, reaction 1 shifts to the left, and $\mathrm{KCl}$ (s) forms on the surface of the probe. Simultaneous addition of $\mathrm{HCl}$ and $\mathrm{SO}_{2}$ gives rise to a mixture of $\mathrm{KCl}$ and $\mathrm{K}_{2} \mathrm{SO}_{4}$ in the deposit. The oxide formed in the base case had a thickness of $\sim 50 \mathrm{~nm}$ (Figure 12). Adding $\mathrm{HCl}$ or $\mathrm{HCl}+\mathrm{SO}_{2}$ to the fuel increased the oxide thickness to $\sim 100 \mathrm{~nm}$. With time, the oxide becomes covered by ash deposits. After exposure to the biomass flue gas environment, the oxide is enriched in potassium, especially in the outer part. Chlorine is not present in the oxide even when $\mathrm{KCl}$ (s) formed on the surface. The oxide formed during $\mathrm{HCl}$ addition is similar to that obtained in furnaces with $\mathrm{O}_{2}$ in the presence of $0.10 \mathrm{mg} \mathrm{cm}^{-2} \mathrm{KCl}$ (s). Exposures of alloy 304 and Sanicro 28 to an $\mathrm{O}_{2}+\mathrm{H}_{2} \mathrm{O}$ environment in the presence of $\mathrm{KCl}(\mathrm{s})$ at $600{ }^{\circ} \mathrm{C}$ showed that $\mathrm{KCl}$ reacts with the protective $(\mathrm{Cr}, \mathrm{Fe})_{2} \mathrm{O}_{3}$ oxide according to reaction 2 , forming $\mathrm{K}_{2} \mathrm{CrO}_{4}$ and poorly protective $\mathrm{Fe}_{2} \mathrm{O}_{3}:^{11,12}$

$$
\begin{array}{r}
\left(\mathrm{Cr}_{x} \mathrm{Fe}_{1-x}\right)_{2} \mathrm{O}_{3}(\mathrm{~s})+4 x \mathrm{KCl}+1.5 x \mathrm{O}_{2}(\mathrm{~g})+2 x \mathrm{H}_{2} \mathrm{O}(\mathrm{g}) \rightarrow \\
(1-x) \mathrm{Fe}_{2} \mathrm{O}_{3}(\mathrm{~s})+2 x \mathrm{~K}_{2} \mathrm{CrO}_{4}(\mathrm{~s})+4 x \mathrm{HCl}(\mathrm{g})
\end{array}
$$

The reaction depletes the oxide in chromium and was reported to trigger rapid oxidation of the alloy, similar to the depletion caused by $\mathrm{CrO}_{2}(\mathrm{OH})_{2}(\mathrm{~g})$.

\section{Comparison with Other Studies}

The results are in qualitative agreement with those of earlier studies in small CFB combustors. The effect of chlorine and sulfur on formation of fine particles has been studied by adding $\mathrm{HCl}$ and $\mathrm{SO}_{2}$ to the reactor to a $50 \mathrm{~kW}$ pilot-scale CFB firing bark and pulp and paper mill sludge. ${ }^{30}$ At low $\mathrm{HCl}$ concentration, a large fraction of alkali was retained in the bottom ash and the concentration of fine particles in the flue gas was relatively low. $\mathrm{HCl}$ addition increased the concentration of fine particles considerably due to gas-phase reactions. $\mathrm{SO}_{2}$ addition transformed some of the chlorides into sulfates in the fineparticle mode. Another study in an entrained flow reactor

(29) Christensen, K. A.; Livbjerg, H. Aerosol Sci. Technol. 2000, 33, 470-489.

(30) Lind, T.; Kauppinen, E. I.; Hokkinen, J.; Jokiniemi, J. K.; Orjala, M.; Aurela, M. Energy Fuels 2006, 20, 61-68. 
showed the effect, on particulate emissions, of combining biomass with sulfur-enriched fuels. ${ }^{31}$ Combustion of pulverized orujillo (a process residue from olive oil production) resulted in a submicron-particle mode composed of $\mathrm{KCl}$ and $\mathrm{K}_{2} \mathrm{SO}_{4}$ in similar proportions. When $\mathrm{SO}_{2}$ or sulfur-containing fuels (coal and coke) were added to the biofuel, chlorine disappeared from the submicron particles. In a second study, the same authors measured the chloride/sulfate ratio in fine particles and showed that it was greatly affected by the initial concentrations of $\mathrm{SO}_{2}$ and $\mathrm{O}_{2}$ in the flue gases. ${ }^{32}$ This dependence could be modeled if the conversion of $\mathrm{SO}_{2}$ to $\mathrm{SO}_{3}$ was assumed to be the only limiting step en route to $\mathrm{K}_{2} \mathrm{SO}_{4}$.

A chemical kinetic model for the gaseous sulfation of alkali hydroxide and alkali chloride has recently been described. ${ }^{33}$ Sulfation is initiated by oxidation of $\mathrm{SO}_{2}$ to $\mathrm{SO}_{3} . \mathrm{SO}_{3}$ subsequently recombines with $\mathrm{KOH}$ or $\mathrm{KCl}$ to form $\mathrm{KHSO}_{4}$ or $\mathrm{KSO}_{3} \mathrm{Cl}$. These species are subsequently converted to alkali sulfate in fast reactions such as $\mathrm{KSO}_{3} \mathrm{Cl}+\mathrm{H}_{2} \mathrm{O} \rightarrow \mathrm{KHSO}_{4}+$ $\mathrm{HCl}$ and $\mathrm{KHSO}_{4}+\mathrm{KCl} \rightarrow \mathrm{K}_{2} \mathrm{SO}_{4}+\mathrm{HCl}$. The oxidation of $\mathrm{SO}_{2}$ to $\mathrm{SO}_{3}$ becomes very slow at temperatures below 1085 $\mathrm{K} .{ }^{30,31,34,35}$ In the present case, the bed temperature was 1123 $\mathrm{K}$ and kinetic limitation of formation of $\mathrm{SO}_{3}$ according to the above mechanism should not be pronounced.

In a related work, ammonium sulfate addition was used to reduce the $\mathrm{KCl}$ levels in two $100 \mathrm{MW}$ biomass-fired fluidizedbed boilers. ${ }^{36}$ A solution of ammonium sulfate was sprayed into the flue gases, and it effectively converted $\mathrm{KCl}$ into $\mathrm{K}_{2} \mathrm{SO}_{4}$, which reduced the deposition rates and halved the corrosion rates for superheater materials.

The transport of potassium compounds to the surface of the deposit probe and the processes on the steel surface should be considered. The flue gas temperature was $\sim 800{ }^{\circ} \mathrm{C}$ at the position of the deposit probe. At this temperature, $\mathrm{KCl}$ exists as gas and $\mathrm{K}_{2} \mathrm{SO}_{4}$ will be in the gas or solid phase, depending on the partial pressure of $\mathrm{K}_{2} \mathrm{SO}_{4}$. Alkalichloride may deposit on superheater surfaces by direct condensation driven by diffusion or indirectly in the form of particles that move toward the surface by diffusion or thermophoresis. Simulations indicate that all processes may be in operation. However, the effect of boundary-layer dynamics on the total alkali chloride deposition rate did not seem to be very strong. ${ }^{37}$

(31) Jiménez, S.; Ballester, J. Combust. Flame 2005, 140, 346-358.

(32) Jiménez, S.; Ballester, J. Proc. Combust. Inst. 2005, 30, 29652972.

(33) Glarborg, P.; Marshall, P. Combust. Flame 2005, 141, 22-39.

(34) Christensen, K. A.; Stenholm, M.; Livbjerg, H. J. Aerosol Sci. 1998 , $29,421-444$

(35) Jensen, J. R.; Nielsen, L. B.; Schultz-Möller, C.; Wedel, S.; Livbjerg, H. Aerosol. Sci. Technol. 2000, 33, 490-509.

(36) Henderson, P.; Szakálos, P.; Pettersson, R.; Andersson, C.; Högberg, J. Mater. Corros. 2006, 57, 128-134.

(37) Pykkönen, J.; Jokiniemi, J. Fuel Process. Technol. 2003, 80, 225262.

\section{Conclusions}

A major result of this work is to demonstrate that the findings in small-scale and lab-scale combustion facilities are valid in a commercial-scale boiler.

A considerable part of the potassium in the fuel is found in the bed, irrespective of addition of $\mathrm{HCl}$ and $\mathrm{SO}_{2}$, obviously a result of the reaction with silica sand. Addition of chlorine to the furnace increases the number and mass of submicron particles in the flue gas because of the formation of potassium chloride that eventually condenses. This was shown by the analysis of the compositions of flue gas, particles, and deposits. These analyses also showed that adding sulfur can shift potassium from reaction with chlorine to reaction with sulfur to form sulfate. One could assume that sulfur would be captured by calcium and remain in the bed, but the rise of sulfur in the bed was quite small. It appears that the sulfur that reacts with calcium ends up in the fly ash. This is supported by the absence of sulfur in the bed and in the gas in the base case.

The particles that are carried by the flue gas have a bimodal size distribution. Volatilization and recondensation are the origin of the submicron part of the size spectrum, to a large fraction consisting of potassium, sulfur, and chlorine, whereas the particles above the micron size range are mostly ash fragments consisting of calcium, magnesium, aluminum, iron, and phosphorus.

The coarse-particle mode is less influenced by the addition of $\mathrm{HCl}$ and $\mathrm{SO}_{2}$. Condensation of volatile gases on large particles as well as chemical reactions cannot be excluded, as the species concerned also occur in the large-particle range. The number size distributions show greater number of particles, displaced toward larger size, with addition of $\mathrm{HCl}$ and $\mathrm{SO}_{2}$ than without addition. This may be a consequence of agglomeration of fine particles facilitated by the denser particle suspension created during the addition of $\mathrm{HCl}$ and $\mathrm{SO}_{2}$.

Because of the short exposure time and relatively low temperature of the deposit probe, corrosion attack is limited. However, adding $\mathrm{HCl}$ to the fuel resulted in a significant increase in the corrosion of alloy 304L. Judging from previous laboratory investigations in similar environments, the acceleration of corrosion is attributed to the reaction of $\mathrm{KCl}$ (formed in the flue gas) with the protective chromium-rich oxide, forming $\mathrm{K}_{2} \mathrm{CrO}_{4}$.

Acknowledgment. This work was supported financially by the Swedish National Energy Administration. Operation of the boiler by personnel from Akademiska Hus, support in sampling and recollection of data from the technical staff of Division of Energy Conversion, and the patient support in carrying out the PCA analyses by Erik Svensson at Department of Chemistry, Atmospheric Science, are gratefully acknowledged.

\section{EF060306C}

